Check for updates

Cite this: Mater. Adv., 2020, 1, 387

Received 28th February 2020 Accepted 28th April 2020

DOI: 10.1039/d0ma00060d

rsc.li/materials-advances

\section{Water-dispersible few-layer graphene flakes for
selective and rapid ion mercury $\left(\mathrm{Hg}^{2+}\right)$-rejecting \\ Water-dispersible few-layer graphene flakes for
selective and rapid ion mercury $\left(\mathrm{Hg}^{2+}\right)$-rejecting membranes $\dagger$}

\author{
Leyla Najafi, ${ }^{a b}$ Reinier Oropesa-Nuñez, (D) ab Beatriz Martín-García, (D) ${ }^{a}$ \\ Filippo Drago, ${ }^{c}$ Mirko Prato, ${ }^{d}$ Vittorio Pellegrini, ${ }^{a b}$ Francesco Bonaccorso (D) ${ }^{\text {ab }}$ and \\ Sebastiano Bellani $\mathbb{D}$ *ab
}

\begin{abstract}
Mercury $(\mathrm{Hg})$ is a global highly toxic pollutant released by both anthropogenic and natural sources. $\mathrm{Hg}$ decontamination is of the utmost importance for human and ecosystem protection. Here, we propose a novel graphene-based membrane capable of performing rapid and highly selective $\mathrm{Hg}^{2+}$-rejection from water. Functionalized graphene flakes are produced by a non-oxidative, room-temperature and post processing-free "green" method to simultaneously exfoliate graphite into single-/few-layer graphene (SLG/FLG) flakes in water and functionalize them with cationic rhodamine 6G (R6G) via a physisorption process (aromatic ring $\pi-\pi$ stacking). The rhodamine 6G-functionalized graphene (R6G-FG) membrane shows a low-density $\left(<0.5 \mathrm{~g} \mathrm{~cm}^{-3}\right)$ packed laminar structure, where R6G molecules act as spacers between the SLG/FLG flakes. The presence of hydrophilic micro/nanodomains in this low-density structure results in a water permeation rate as high as $789.6 \mathrm{~L} \mathrm{~m}^{-2} \mathrm{~h}^{-1}$ bar $^{-1}$ (for an $80 \mu \mathrm{m}$-thick membrane, R6G-FG mass loading of $3.58 \mathrm{~g} \mathrm{~m}^{-2}$ ). Meanwhile, the R6G-FG complexes perform as ionselective nano-traps for $\mathrm{Hg}^{2+}$, showing almost complete rejection (>99\%) for a filtered solution volume normalized to the R6G-FG mass superior to $3 \mathrm{~L} \mathrm{~g}^{-1}$. The selective rejection capability of the R6G-FG membrane is ruled by competitive adsorption of metal ions and positively charged R6G molecules with different affinity onto the negatively charged graphene surface. Lastly, a washing treatment in alkaline conditions is also proposed for membrane regeneration and reuse. The rationalization of the working mechanism of the R6G-FG membrane is promising for eliminating the "permeability-selectivity trade-offs" often tackled by laminar two-dimensional material membranes.
\end{abstract}

\section{Introduction}

The lack of clean water and sanitation is a pervasive problem afflicting the world today. ${ }^{1,2}$ This is expected to get worse in the coming years, ${ }^{3}$ unless efficient water purification methods are developed while minimizing the use of hazardous/toxic chemicals and impact on the environment. ${ }^{4-8}$ In this scenario, two-dimensional (2D) materials are gaining massive appeal for the realization of novel membranes for filtration, ${ }^{9,10}$ water

\footnotetext{
${ }^{a}$ Graphene Labs, Istituto Italiano di Tecnologia, via Morego 30, 16163, Genova, Italy

${ }^{b}$ BeDimensional Spa, Via Albisola 121, 16163 Genova, Italy. E-mail: s.bellani@bedimensional.it

${ }^{c}$ NanoChemistry, Istituto Italiano di Tecnologia, via Morego 30, 16163 Genova, Italy

${ }^{d}$ Materials Characterization Facility, Istituto Italiano di Tecnologia, via Morego 30, 16163 Genova, Italy

† Electronic supplementary information (ESI) available. See DOI: 10.1039/ d0ma00060d
}

purification $^{11,12}$ and desalination technologies. ${ }^{11-18}$ As keycases, graphene based-membranes can provide cost-effective solutions for precise and ultrafast ionic and molecular sieving in aqueous solution. ${ }^{19-24}$ Recently, other 2D materials, such as transition metal dichalcogenides (TMDs), ${ }^{25-27}$ boron nitride (BN), ${ }^{28}$ MXenes $^{29}$ and layered double hydroxides (LDHs), ${ }^{30,31}$ have been also reported for molecular and ionic separation membranes. $^{32,33}$ The effectiveness of 2D material-based membranes originates from their unique laminar structure consisting of nanochannels with tunable sizes ${ }^{32-34}$ and surface chemistry. ${ }^{35,36}$ These features can simultaneously provide selective solute rejection ${ }^{34,37,38}$ and high solvent flux ${ }^{25,39,40}$ (i.e., water permeation rate under external pressure $>500 \mathrm{~L} \mathrm{~m}^{-2} \mathrm{~h}^{-1} \mathrm{bar}^{-1}$ for $\mu$ m-thick membranes). ${ }^{41,42}$ The rejection selectivity results from a combination of size-exclusion effects depending on the interlayer spacing of the $2 \mathrm{D}$ material flakes, ${ }^{32-34}$ electrostatic interactions between the charged solute and the charged surface state of the flakes, ${ }^{21,35,36}$ and adsorption effects (e.g., ion $-\pi$ interactions ${ }^{43,44}$ and metal coordination to the flakes' 
surface $\left.{ }^{45-47}\right)$. For the case of water as a solvent, the unusual high flow rate (up to $20 \mathrm{~m} \mathrm{~s}^{-1}$ ) has been attributed to both capillary driven force and low-friction flow confined within $2 \mathrm{D}$ channels enclosed by hydrophobic, pristine (non-oxidized) regions of graphene. ${ }^{20,48}$ In contrast, H-bonding interactions between water molecules and O-containing functional groups slow down the water flow between the hydrophilic oxidized graphene flakes. ${ }^{49}$ Moreover, the interaction between hydrophilic regions and water causes the swelling of the soaked membranes, ${ }^{50,51}$ which progressively decreases their solute rejection capability. ${ }^{10,52}$

Although the morphological and physicochemical properties of 2D materials hold promise for the development of nextgeneration ultrathin, high-flux, and energy-efficient membranes for precise ionic and molecular filtration, ${ }^{53,54}$ a major challenge that practically hinders their implementation is the production of $2 \mathrm{D}$ materials at an industrial scale together with controlling their physical/chemical properties at the nanoscale. ${ }^{13,55,56}$ In this context, liquid phase exfoliation (LPE) methods ${ }^{57-60}$ have emerged as scalable approaches to exfoliate layered bulk crystals into single-/few-layer flakes in liquid solvents by exploiting cavitation ${ }^{61-65}$ and shear forces ${ }^{66-71}$ to break the van der Waals bonds between the adjacent planes of the layered structures. Then, the exfoliated flakes can be deposited or printed on different substrates using well-known solutionprocessing techniques. ${ }^{72-75}$ Among LPE techniques, ultrasonication-assisted exfoliation is the most used lab-scale approach because of its easiness. ${ }^{57,59,61}$ Its optimization also provides guidelines for designing advanced LPE processes with industrial material production rates (up to the order of $1 \mathrm{~kg}$ per day, independently of the materials). ${ }^{71,76-78}$ Subsequently, the produced nanomaterials have to be exploited in the form of interlocked layered structures to effectively act as robust ion and/or molecule filters..$^{9-14}$ At this stage, the inclusion of different-sized functional groups ${ }^{36,79}$ can act as both nanometric spacers modulating the nanochannels' size $\mathrm{e}^{19,21,80}$ and active sites for chemical adsorption of solutes, ${ }^{25,81,82}$ resulting in extraordinary control of the permeation selectivity. ${ }^{83-86}$ Actually, the possibility of functionalizing 2D materials, ${ }^{87}$ which intrinsically provide a platform of nanomaterials covering a unique variety of physical/chemical properties, ${ }^{88-91}$ can create added-value for designing laminar structures with "on-demand" solute-selective removal and solvent permeability. ${ }^{21,53,54}$ The resulting membrane can be effectively integrated in multifunctional and multi-stage filtration apparatus based on sub-cascade membranes and/or treatment. ${ }^{92-95}$ This also turns out to minimize fouling invasion, ${ }^{94-97}$ which reduces the solvent permeability and solute affinity in the endlocated nano-filtration blocks. ${ }^{94,95,98-100}$

Herein, we show a novel membrane based on graphene functionalized with cationic rhodamine 6G - R6G - (hereafter named R6G-FG), a prototypical cost-effective and non-hazardous organic molecule, ${ }^{101,102}$ for selective $\mathrm{Hg}^{2+}$-rejection from water. It is noteworthy that $\mathrm{Hg}$ is one of the heavy metals of most concern, since its non-biodegradability and bio-accumulative pollution are the cause of birth defects, brain damage and diseases in humans and wildlife. ${ }^{103}$ Mercury is released into the environment by anthropogenic sources in the form of several industry products/byproducts and processes ${ }^{104-107}$ including gold mining by amalgamation, ${ }^{108}$ chlor-alkali industry wastewater, ${ }^{109,110}$ cement and mineral production, ${ }^{111}$ combustion in coal-fired power plants, ${ }^{112-114}$ port activities, ${ }^{115}$ petroleum refineries, ${ }^{116,117}$ batteries $^{118}$ and fluorescent lamps. ${ }^{119}$ In addition, volcanic eruptions, ${ }^{120}$ deposits of cinnabar ${ }^{121,122}$ and trace amounts in coal $^{123,124}$ are relevant natural sources of $\mathrm{Hg}$ emission. ${ }^{125,126} \mathrm{In}$ order to face $\mathrm{Hg}$ pollution, global agreements have been reached for implementing $\mathrm{Hg}$ treaties. ${ }^{127-129}$ This is spurring the search for novel efficient and rapid methods to remove and recover $\mathrm{Hg}$ from water, ${ }^{130-133}$ where the volatile elemental $\mathrm{Hg}$ $\left(\mathrm{Hg}^{0}\right)$ penetrates via wet precipitation once is oxidized in $\mathrm{Hg}$ (II) form. ${ }^{134,135}$ The rational choice of R6G-based functionalization of graphene for $\mathrm{Hg}^{2+}$ removal is based on the previous use of R6G molecules pre-adsorbed on conductive substrates as fluorescence/surface-enhanced Raman scattering (SERS) chemo-sensors for the selective detection of $\mathrm{Hg}^{2+} \cdot{ }^{136-141}$ R6G-FG was produced by a non-oxidative, room-temperature and post processing-free "green" method to simultaneously exfoliate graphite up to single-/few-layer flakes in water (mild alkaline conditions, $\mathrm{pH}$ 8) and functionalize graphene with R6G. This method is effective to obtain graphene flakes with a large contribution of monolayers/bilayers and lateral size comparable to that obtained by conventional LPE methods, e.g., the prototypical ultrasonication-aided exfoliation in $N$-methyl-2-pyrrolidone (NMP). ${ }^{57,59,61,142,143}$ Subsequently, selective and rapid $\mathrm{Hg}^{2+}$-rejecting membranes, made of R6Gincorporated graphene interlocked layered structures (R6G-FG membranes), were obtained through facile low-pressure (1 bar) deposition (i.e., vacuum filtration) of the as-produced R6G-FG dispersions. The R6G molecules act as spacers between the graphene flakes and determine the presence of hydrophilic micro/nanodomains, enabling efficient water permeation (up to $789.6 \mathrm{~L} \mathrm{~m}^{-2} \mathrm{~h}^{-1}$ bar $^{-1}$ for an $80 \mu \mathrm{m}$-thick membrane). Meanwhile, R6G/graphene complexes perform as ion-selective nano-traps for $\mathrm{Hg}^{2+}$ (percentage $\mathrm{Hg}^{2+}$ rejection higher than $99 \%)$. The ion selective permeation is explained by the $\mathrm{Hg}$-philicity of graphene flakes, which results in adsorption of $\mathrm{Hg}^{2+}$ replacing the R6G molecules. In contrast, the metallophilicity of the graphene flakes for the other investigated metal ions is insufficient to compete with R6G molecules, still saturating the cation-sieving sites of graphene flakes. Lastly, the recyclability of the R6G-FG membranes, i.e., the recovery of their $\mathrm{Hg}^{2+}$ adsorption capability, was attained by washing the membranes in tetrabutylammonium hydroxide 30-hydrate $\left(\mathrm{Bu}_{4} \mathrm{NOH} \cdot 30 \mathrm{H}_{2} \mathrm{O}\right)$, representing a novel pH-controlled membrane regeneration method.

\section{Experimental}

\section{Production of materials}

Rhodamine 6G-functionalized graphene samples were produced in the form of an aqueous dispersion through ultrasonicationassisted LPE of graphite in water, in the presence of R6G 
molecules and mildly alkaline conditions. Experimentally, $1 \mathrm{~g}$ of graphite (+100 mesh, $\geq 75 \% \mathrm{~min}$, Sigma Aldrich) and $1.2 \mathrm{mg}$ of R6G powder (99\% dye content, Sigma Aldrich) were dispersed in $100 \mathrm{~mL}$ of deionized water. The $\mathrm{pH}$ of the sample was adjusted to $\sim 8.0$ by adding drops of $1 \mathrm{M} \mathrm{KOH}$ solution (Sigma Aldrich). The sample was ultrasonicated in a bath sonicator (Branson 5800 cleaner, Branson Ultrasonics) for $6 \mathrm{~h}$. Afterward, the sample was centrifuged at $500 \mathrm{~g}$ for $30 \mathrm{~min}$ at $15{ }^{\circ} \mathrm{C}$ to exploit sedimentation-based separation. ${ }^{142-145}$ Lastly, $\sim 80 \%$ of the supernatant was collected by pipetting, obtaining the R6G-FG dispersion in water.

\section{Characterization of materials}

Zeta potential measurements of the as produced R6G-FG in the form of a water dispersion were carried out with a Zetasizer Nano ${ }^{\circledR}$ series (Malvern Instruments) using a disposable capillary cell (DTS 1060) at room temperature for the graphene and R6G-FG water dispersion. Concretely, the electrophoretic mobility was measured and converted into the zeta potential using the Smoluchowski approximation. ${ }^{146}$ An equilibration time of $3 \mathrm{~min}$ was set before each measurement. The zeta potential value was averaged over the values obtained by 3 replicate measurements.

Transmission electron microscopy (TEM) images were taken with a JEM 1011 (JEOL) transmission electron microscope operating at $100 \mathrm{kV}$. Morphological and statistical analysis were carried out using ImageJ software (NIH) and OriginPro 9.1 software (OriginLab), respectively. The lateral dimension of a flake was estimated as its maximum lateral dimension. The samples for the TEM measurements were prepared by dropcasting the R6G-FG dispersions onto carbon-coated $\mathrm{Cu}$ grids, subsequently rinsed with deionized water and dried under a vacuum overnight.

Atomic force microscopy (AFM) images were taken using a Nanowizard III (JPK Instruments, Germany) mounted on an Axio Observer D1 (Carl Zeiss, Germany) inverted optical microscope. The AFM measurements were carried out using PPP-NCHR cantilevers (Nanosensors, USA) with a nominal tip diameter of $10 \mathrm{~nm}$. A drive frequency of $\sim 295 \mathrm{kHz}$ is used. Intermittent contact mode AFM images $(512 \times 512$ data points) of $2.5 \times 2.5 \mu^{2}$ were collected by keeping the working set point above $70 \%$ of the free oscillation amplitude. The scan rate for acquisition of images was $0.7 \mathrm{~Hz}$. Height profiles were processed with the JPK Data Processing software (JPK Instruments, Germany) and the data were analyzed with OriginPro 9.1 software. Statistical analysis was carried out by means of Origin 9.1 software on multiple AFM images for each sample. The samples were prepared by drop-casting R6G-FG dispersions onto mica sheets (G250-1, Agar Scientific Ltd, Essex, UK) and dried under a vacuum.

Raman spectroscopy measurements were carried out using a Renishaw microRaman inVia 1000 using a $50 \times$ objective, with an excitation wavelength of $532 \mathrm{~nm}$ and an incident power on the samples of $1 \mathrm{~mW}$. For each sample, 50 spectra were collected. The samples were prepared by drop casting the R6G-FG and R6G dispersions onto $\mathrm{Si} / \mathrm{SiO}_{2}$ substrates and dried under a vacuum.
X-ray photoelectron spectroscopy (XPS) characterization was carried out on a Kratos Axis UltraDLD spectrometer, using a monochromatic $\mathrm{Al} \mathrm{K} \alpha$ source $(15 \mathrm{kV}, 20 \mathrm{~mA})$. The spectra were taken over a $300 \times 700 \mu^{2}$ area. Wide scans were collected with a constant pass energy of $160 \mathrm{eV}$ and energy step of $1 \mathrm{eV}$. High-resolution spectra were acquired at a constant pass energy of $10 \mathrm{eV}$ and energy step of $0.1 \mathrm{eV}$. The binding energy scale was referenced to the $\mathrm{C} 1 \mathrm{~s}$ peak at $284.8 \mathrm{eV}$. The spectra were analyzed using the CasaXPS software (version 2.3.17). The samples were prepared by drop-casting R6G dispersions onto $\mathrm{Si} / \mathrm{SiO}_{2}$ substrates (LDB Technologies Ltd) and dried under a vacuum.

The steady-state photoluminescence (PL) emission measurements were performed using an Edinburgh Instruments FLS920 spectrofluorometer. The samples were a R6G solution in water at a concentration of $0.2 \mathrm{mM}$ and a 1:100 diluted R6G-FG dispersion, both with and without $\mathrm{Hg}^{2+}$. For the PL experiments with $\mathrm{Hg}^{2+}$, an aqueous solution of $\mathrm{Hg}^{2+}$ (10 ppm) was prepared by dissolving $\mathrm{Hg}\left(\mathrm{ClO}_{4}\right)_{2}$ salt (Sigma Aldrich, $\left.\mathrm{Hg}\left(\mathrm{ClO}_{4}\right)_{2} \cdot x \mathrm{H}_{2} \mathrm{O}, 98 \%\right)$ in water. From this solution, different aliquots were taken and added to the R6G-FG dispersion in water $\left(\sim 0.4 \mathrm{mg} \mathrm{mL}^{-1}\right)$. The PL spectra were collected exciting the samples at $400 \mathrm{~nm}$ using a Xe lamp coupled to a monochromator and using quartz cuvettes with a path length of $1 \mathrm{~cm}$. The blank (control) measurement was carried out in the same experimental conditions used for the characterization of the aforementioned samples in order to discard any contribution from the solvent. Additionally, before carrying out the PL measurements, the absorbance of the different samples was acquired using a Varian Cary 5000 UV-vis-NIR spectrophotometer. The PL spectra of the samples were then normalized to the absorbance of the samples at the excitation wavelength $(400 \mathrm{~nm})$ to allow their comparison.

\section{Fabrication of the membranes}

The membranes were produced by depositing the R6G-FG dispersion in water onto a microporous nylon filter (Whatman ${ }^{\circledR}$ membrane filters nylon, $0.2 \mu \mathrm{m}$ pore size, Sigma Aldrich) through the vacuum filtration process. By controlling the volume of the deposited dispersion, different amounts of material were deposited (mass loading ranging from 17.9 to $71.6 \mathrm{~g} \mathrm{~m}^{-2}$ ). The membranes were dried overnight at room temperature before their characterization.

\section{Characterization of the membranes}

Scanning electron microscopy (SEM) analysis of the membranes was performed using a Helios Nanolab 600 DualBeam microscope (FEI Company) operating at $5 \mathrm{kV}$ and $0.2 \mathrm{nA}$. The EDX spectra were acquired by combining the microscope (operating at $15 \mathrm{kV}$ and $0.8 \mathrm{nA}$ ), an X-Max detector and an INCA system (Oxford Instruments). The samples were imaged without any metal coating or pretreatment. To evaluate the laminar structure of the membranes by the cross section, the membranes were cut with a scalpel and mounted in a tilted sample holder.

Atomic force microscopy measurements were taken with the same setup used for the material characterization. 
However, the AFM mode was QI for morphology and adhesion work. Adhesion work measurements were also carried out with the same AFM setup, but used in the quantitative imaging (QI) mode, ${ }^{147}$ an AFM mode based on force measurements. V-shaped DNP silicon nitride cantilevers (Bruker, Billerica, MA, USA), with a nominal spring constant of $0.06 \mathrm{~N} \mathrm{~m}^{-1}$, resonance frequency in air in the $40-70 \mathrm{kHz}$ range and tip typical curvature radius of $20-60 \mathrm{~nm}$ were used. The actual spring constant of each cantilever was determined in situ, using the thermal noise method. The acquisition of a large set of force-distance $(\mathrm{FD})$ curves $(256 \times 256)$ was performed with a maximum force load of $25 \mathrm{nN}$ and a curve length of $800 \mathrm{~nm}$. $3 \times 3 \mu \mathrm{m}^{2}$ images were collected. Height profiles were processed with JPK Data Processing software (JPK Instruments, Germany) and the data were analyzed with OriginPro 9.1 software.

Electrical volumetric resistance measurements of the membranes were performed using a four-probe system (Jandel RM3000 Test Unit).

Elemental analysis by inductively coupled plasma optical emission spectroscopy (ICP-EOS) was performed with a ThermoFisher ICAP 6000 Duo inductively coupled plasma optical emission spectrometer. The samples were prepared from stock solutions recovered after passing through the membranes and digesting in $\mathrm{HCl}: \mathrm{HNO}_{3}(3: 1 \mathrm{vol} / \mathrm{vol})$ overnight. The stock solutions, i.e., $10 \mathrm{ppm}$ aqueous solutions of: $\mathrm{CaCl}_{2}, \mathrm{MnCl}_{2}$, $\mathrm{CoCl}_{2}, \mathrm{NiCl}_{2}, \mathrm{CuCl}_{2}, \mathrm{ZnCl}_{2}, \mathrm{CdCl}_{2}$, and $\mathrm{Hg}\left(\mathrm{ClO}_{4}\right)^{2}$ (chemicals supplied by Sigma Aldrich), were also measured by ICP-OES. Experimentally, the analyzed solutions were prepared in a $25 \mathrm{~mL}$ volumetric flask. Prior to the measurement, $2.5 \mathrm{~mL}$ of each sample was diluted with Millipore water to a total volume of $25 \mathrm{~mL}$ and stirred by vortexing at $2400 \mathrm{rpm}$ for 10 s. Lastly, the sample was filtered using a PTFE membrane (0.45 $\mu \mathrm{m}$ pore size). Four measurements were performed on each sample to obtain the final averaged values of the metals' concentration.

\section{Results and discussion}

\section{Production and characterization of R6G-FG}

Single/few-layer graphene flakes were produced by ultrasonicationassisted LPE of graphite in mild-alkaline water (obtained by adding $1 \mathrm{M} \mathrm{KOH}$ to adjust the $\mathrm{pH}$ equal to 8 ) in the presence of R6G molecules (12 $\mathrm{mg} \mathrm{L}^{-1}$ ) (Fig. 1a). By excluding the $\mathrm{KOH}$ or the R6G as additives, the exfoliation was not effective, resulting in the precipitation of the aggregates. In agreement with computational $^{148}$ and experimental studies, ${ }^{148-151}$ R6G molecules interact with the graphene surface by forming physisorbed

a)
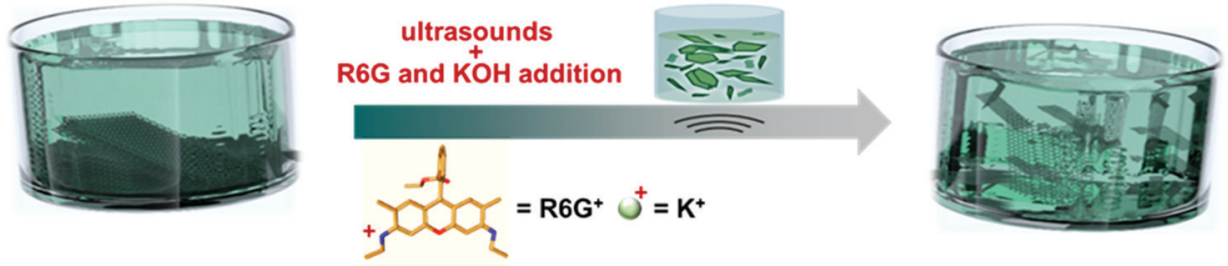

b)

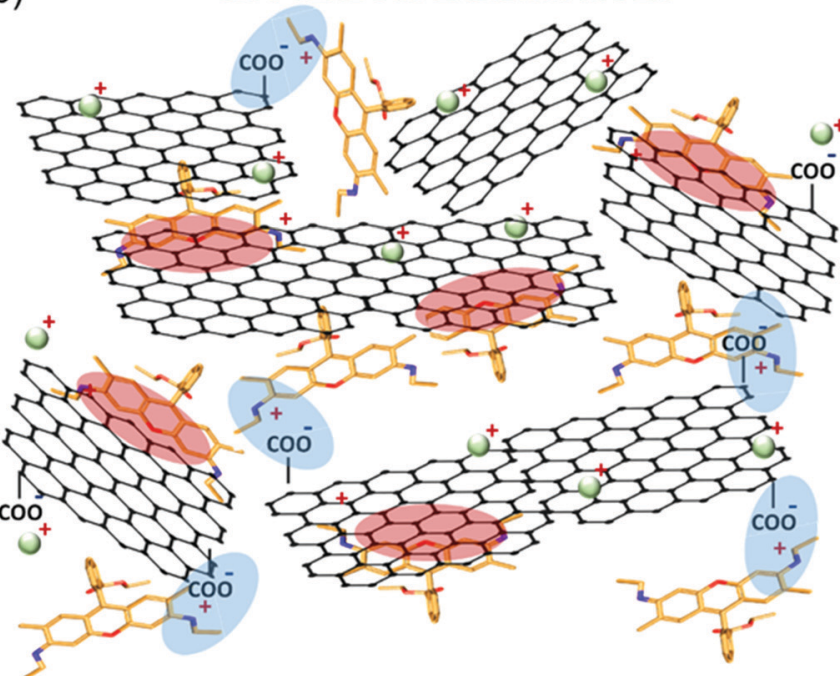

C)SEDIMENTATION-BASED SEPARATION

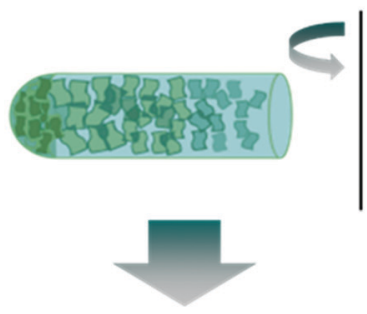

EXFOLIATED FLAKES

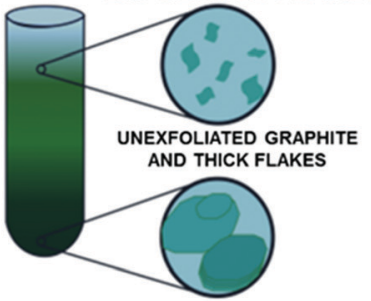

$=$ electrostatic interaction $=\pi-\pi$ interaction

Fig. 1 Production of R6G-FG through ultrasonication-assisted LPE in water. (a) Sketch of the exfoliation of graphite through ultrasonication-assisted LPE in water in the presence of R6G molecules $\left(12 \mathrm{mg} \mathrm{L}^{-1}\right)$ and a small amount of $\mathrm{KOH}(\mathrm{pH}=8)$. (b) Representation of the physisorption of the R6G molecules on the graphene flakes by electrostatic and $\pi-\pi$ interactions. (c) Illustration of the sedimentation-based separation process used to collect the exfoliated sample (R6G-FG dispersion in water). 
complexes (Fig. 1b). ${ }^{148-151}$ The physisorption behavior originates from the $\pi-\pi$ stacking between the aromatic rings of the R6G molecules and graphene, ${ }^{148-152}$ as well as the electrostatic interaction between positively-charged amino groups of R6G molecules and negatively charged intrinsic functional groups of graphene, ${ }^{148,149}$ i.e., deprotonated carboxyl groups at the edges and/or hydroxyl and epoxy groups on the basal plane for marginal oxidized regions (see the below XPS analysis). ${ }^{153}$

The electrostatic R6G/graphene interaction is also aided by mild alkaline conditions, as obtained by $\mathrm{KOH}$ addition in water. In fact, the alkaline environment completes the dissociation of the R6G from the neutral to the cationic form, thus triggering its electrostatic interaction with the negative surface of graphene, whose deprotonated state is also promoted in alkaline conditions, ${ }^{153}$ as observed for graphene derivative dispersons. ${ }^{154-156}$ Furthermore, the carboxyl protons at the edges of graphene first undergo ion exchange with salt cations
$\left(\mathrm{K}^{+}\right){ }^{149,157}$ which further eases graphite exfoliation, and thus the graphene/R6G interaction. ${ }^{149,157}$

Subsequent to the ultrasonication process, sedimentationbased separation based on ultracentrifugation (see the Experimental section) was used to remove unexfoliated materials and thick flakes and collect the supernatant as the exfoliated material in a concentration of $\sim 0.4 \mathrm{mg} \mathrm{mL}^{-1}$ (Fig. 1c).

The stability of the as-produced aqueous dispersion of graphene flakes was verified by measuring the graphene flake zeta-potential, i.e., the electric potential at the interfacial double layer of dispersed flakes versus a point in the continuous phase away from the interface. ${ }^{158}$ The measured graphene flake zeta potential is $\sim-32 \mathrm{mV}$, which indicates that the as-produced graphene flake dispersion is electrically stabilized (i.e., electrically repulsive forces between the flakes exceed their mutually attractive van der Waals force). ${ }^{153,159}$ Transmission electron microscopy and AFM measurements (Fig. 2a and b)
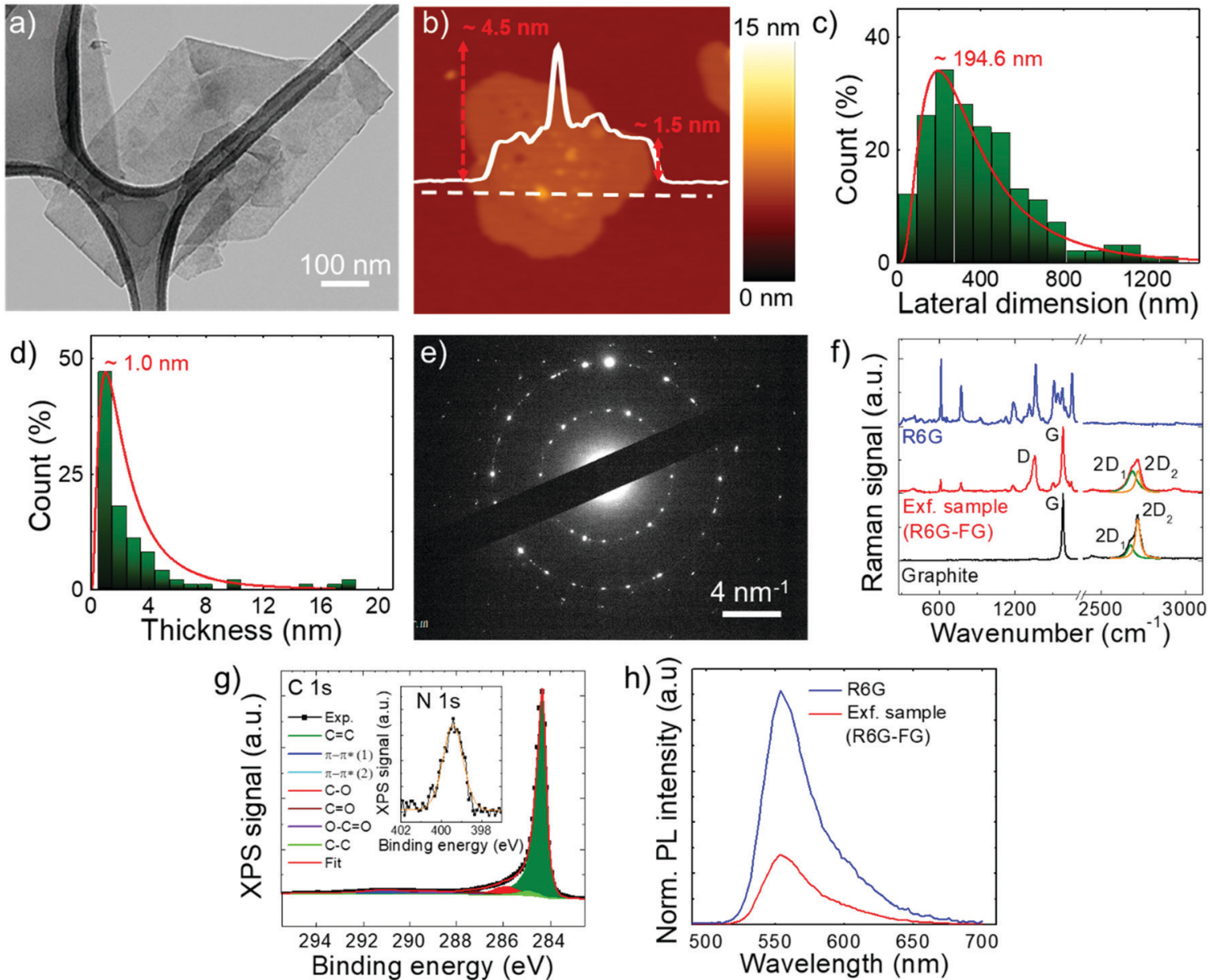

Fig. 2 Characterization of as produced R6G-FG flakes. (a and b) Representative TEM and AFM images of the R6G-FG flakes. (c) TEM statistical analysis of the lateral dimension of R6G-FG flakes (calculated on 120 flakes). (d) AFM statistical analysis of the thickness of the R6G-FG flakes (calculated on 120 flakes). (e) Electron diffraction pattern of the TEM image shown in (a), revealing the crystallinity of the R6G-FG flakes. (f) Comparison between the Raman spectra of graphite (black), R6G-FG (red) and R6G molecules (blue). The multi-peak Lorentzian fittings of the 2D mode region of the spectra of graphite and R6G-FG show the contribution of $2 \mathrm{D}_{1}$ (orange) and $2 \mathrm{D}_{2}$ (olive) modes. (g) $\mathrm{C}$ 1s XPS spectrum of R6G-FG, together with its deconvolution evidencing the bands ascribed to $\mathrm{C}=\mathrm{C}, \mathrm{C}-\mathrm{C}, \mathrm{C}-\mathrm{N}, \mathrm{C}=\mathrm{O}$ and $\pi-\pi^{*}$. The inset shows the $\mathrm{N}$ 1s XPS spectrum ascribed to the presence of R6G molecules adsorbed to the surface of graphene flakes. (h) PL spectra of R6G (blue) and R6G-FG (red) in water, normalized to the absorbance of the samples at the excitation wavelength $(400 \mathrm{~nm})$. 
show that the exfoliated sample consists of irregularly-shaped wrinkled flakes with a log-normally distributed lateral dimension and thickness of $194.6 \mathrm{~nm}$ and $1.0 \mathrm{~nm}$, respectively (Fig. 2c and d). The TEM diffraction pattern of the imaged flakes is shown in Fig. 2e and indicates the crystalline nature of the flakes. The structural properties of the latter have been further investigated by Raman spectroscopy, which is a versatile tool to identify both chemical and physical properties of graphitic materials. ${ }^{160}$ The typical Raman spectrum of exfoliated graphene flakes shows, as fingerprints, the following peaks: ${ }^{142,161-163} \mathrm{G}$ $\left(\mathrm{E}_{2 \mathrm{~g}}\right.$ phonon at the Brillouin zone centre, $\left.\sim 1585 \mathrm{~cm}^{-1}\right),{ }^{161,162,164}$ $\mathrm{D}$ (breathing mode of $\mathrm{sp}^{2}$ rings requiring a defect for its activation by double resonance, $\left.\sim 1380 \mathrm{~cm}^{-1}\right),{ }^{162,164-166}$ $\mathrm{D}^{\prime}\left(\sim 1620 \mathrm{~cm}^{-1}\right)^{167}$ and $2 \mathrm{D}\left(\sim 2700 \mathrm{~cm}^{-1}\right)^{162}$ (see the ESI $\dagger$ for a detailed discussion of the origin of the Raman modes). Fig. 2f shows the Raman spectra of the graphite and the as-produced flakes. The Raman spectrum of only R6G is also shown to prove the R6G-functionalization of the graphene flakes, as well as to discriminate the peaks related to graphitic components from those attributed to R6G molecules. For the exfoliated sample, the $\mathrm{D}$ and $\mathrm{D}^{\prime}$ bands increase relatively to the $\mathrm{G}$ band compared to the graphite case. The ratio between the intensities of the $\mathrm{D}$ and $\mathrm{G}$ peaks $-I(\mathrm{D}) / I(\mathrm{G})-$ is $\sim 0.6$, which is significantly superior to that of pristine graphite $(<0.1)$. This indicates that few $(<5)$-layer graphene flakes have been effectively produced by our method, in agreement with AFM analysis. ${ }^{168-171}$ The analysis of the $2 \mathrm{D}$ peak allows the exfoliation of the graphite into few-layer graphene to be further confirmed. In fact, the $2 \mathrm{D}$ peak is a single and sharp Lorentzian band centred at $\sim 2680 \mathrm{~cm}^{-1}$ for single-layer graphene, ${ }^{142,161,162}$ whereas it is a superposition of multiple components, the main being the $2 \mathrm{D}_{1}$ and $2 \mathrm{D}_{2}$ components, for few-layer graphene. ${ }^{142,161,162}$ In graphite, the intensity of the $2 \mathrm{D}_{2}$ band is twice the $2 \mathrm{D}_{1}$ band, ${ }^{161,162,172}$ while the $2 \mathrm{D}_{2}$ progressively decreases with decreasing the number of layers for few-layer graphene. ${ }^{161,162,169,172,173}$ Therefore, the data shown in Fig. 2f clearly indicate that the exfoliated sample has a few-layer graphene enriched composition, ${ }^{174}$ since $I\left(2 \mathrm{D}_{2}\right)$ is inferior to $I\left(2 D_{1}\right) .{ }^{161,162,169,172,173}$ Lastly, the Raman spectrum of the exfoliated sample exhibits additional signatures which are attributed to the R6G bands, in agreement with previous studies. $^{175-179}$ Notably, some of the bands related to R6G partially overlap those typically observed for graphene including $\mathrm{D}, \mathrm{G}$ and $\mathrm{D}^{\prime}$. This results in a broadening of the $\mathrm{D}, \mathrm{G}$ and $\mathrm{D}^{\prime}$ bands assigned to graphene, as well as a slight overestimation of the calculated $I(D) / I(G)$. For the sake of comparison, a representative Raman spectrum for graphene flakes produced by conventional LPE in NMP is reported in Fig. S1 (ESI $\dagger$ ) to uniquely identify the Raman modes of graphene in the absence of R6G molecules. The chemical composition of the as-produced graphene flakes has been assessed by performing XPS measurements (Fig. 2g). The C 1s spectrum of the flakes can be decomposed into different components. The main one peaks at $(284.3 \pm 0.2) \mathrm{eV}$ and refers to $\mathrm{C}=\mathrm{C}$ ( $\mathrm{sp}^{2}$ carbon) ${ }^{180-182}$ which also results in the corresponding feature at $(291.1 \pm 0.2) \mathrm{eV}$ due to $\pi-\pi^{*}$ interactions. ${ }^{180-182}$ The component centred at $284.8 \mathrm{eV}$ refers to $\mathrm{C}-\mathrm{C}\left(\mathrm{sp}^{3}\right)^{182,183}$ and it is due to flake edges as well as to environmental contamination (adventitious carbon). ${ }^{184}$ The other contributions, peaking at binding energies of $\sim 285.9 \mathrm{eV}$, $287.2 \mathrm{eV}$ and $289.1 \mathrm{eV}$, can be ascribed to $\mathrm{C}-\mathrm{O} / \mathrm{C}-\mathrm{N}, \mathrm{C}=\mathrm{O}$ and $\mathrm{O}=\mathrm{C}-\mathrm{O}$ groups, respectively. ${ }^{185,186}$ Their origin is ascribed to R6G molecules, ${ }^{185,186}$ whose presence is confirmed by the peak at $399.4 \mathrm{eV}$ in the $\mathrm{N}$ 1s spectrum (inset of Fig. 2g) corresponding to their amine groups. The percentage content of $\mathrm{O}$ is inferior to $2.5 \%$, thus proving the high quality of the as-produced graphene flakes. It is noteworthy that the low oxidation of graphene can be also explained by the removal of epoxy and hydroxyl groups attached to the graphene surface by the R6G molecules nearby. ${ }^{148}$ In more detail, a R6G molecule close to an epoxy/hydroxyl group on graphene can cause the detachment of $\mathrm{O} / \mathrm{OH}$ species from the graphene flake by forming a $\mathrm{N}-\mathrm{O}$ bond with the amine group of R6G. Subsequently, the R6G molecule can further interact with graphene through physisorption mechanisms. The formed system decreases the energy of the oxidized graphene by more than $2 \mathrm{eV}$, while showing an electronic structure of the reduced graphene resembling the one of the pristine graphene. ${ }^{148}$ The occurrence of an interaction between graphene flakes and R6G molecules was further confirmed by steady-state PL measurements. As shown in Fig. 2h, the PL emission of R6G molecules in aqueous solution is quenched in the presence of graphene. In agreement with previous studies, the PL quenching is linked to the formation of R6G/graphene complexes leading to photo-induced electron transfer from R6G to graphene. ${ }^{150,151,187,188}$ Overall, the morphological and spectroscopic characterization of the exfoliated sample confirm that the R6G/KOH-assisted LPE of graphite in water is effective for producing high quality R6G-functionalized single-/few-layer graphene flakes.

\section{Fabrication and morphological characterization of graphene- based laminar membranes}

The aqueous R6G-FG dispersion was deposited onto a microporous nylon membrane (pore size of $0.2 \mu \mathrm{m}$ ) through a vacuum filtration process to obtain graphene-based laminar membranes (R6G-FG membranes) with mechanical robustness. By controlling the volume of the deposited dispersion, different amounts of material were deposited over the supporting membranes (mass loading ranging from 17.9 to $71.6 \mathrm{~g} \mathrm{~m}^{-2}$ ). Noteworthily, functionalization of 2D material-based membranes with dye molecules has been previously reported. ${ }^{25}$ However, these cases achieved the functionalization by postdeposition treatment of the membranes through a chemical bath in dye solutions over a long time (tens of days). ${ }^{25}$ Therefore, this approach may be time-consuming for pursuing scalable technologies.

Fig. 3a shows a photograph of a representative nylon filtersupported membrane (R6G-FG mass loading of $35.8 \mathrm{~g} \mathrm{~m}^{-2}$ ), also illustrating its mechanical flexibility. The surface morphology of the as-prepared membranes has been characterized by SEM and AFM measurements. Fig. 3b shows the top-view SEM image of the R6G-FG membrane reported in Fig. 3a. The image indicates that the membrane has a crumpled, wrinkled, and flake-composed structure. 

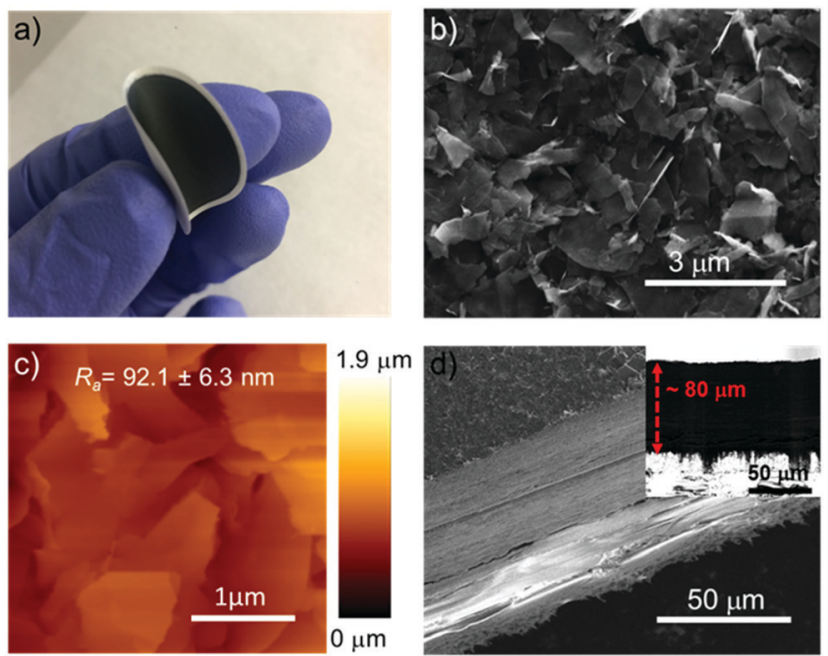

Fig. 3 Morphological characterization of the R6G-FG membranes (a) Photograph of the nylon filter-supported R6G-FG membrane, illustrating its mechanical flexibility. (b) Top-view SEM and (c) AFM images of a representative R6G-FG membrane (R6G-FG mass loading of $35.8 \mathrm{~g} \mathrm{~m}^{-2}$ ). The $R_{\mathrm{a}}$ value is also reported in (c). (d) Cross-sectional SEM image of the same R6G-FG membrane reported in (b and c), showing its laminar structure. The inset shows the un-tilted cross-section SEM image of the R6G-FG membrane, used for estimating its thickness.

The atomic force microscopy image (Fig. 3c) also confirms such a surface structure, which exhibits an average roughness $\left(R_{\mathrm{a}}\right)$ of $92.1 \pm 6.3 \mathrm{~nm}$. Fig. 3d reports cross-sectional SEM images of a representative membrane (R6G-FG mass loading of $35.8 \mathrm{~g} \mathrm{~m}^{-2}$ ), evidencing a $\sim 80 \mu \mathrm{m}$-thick laminar structure. The corresponding mass density of the membrane is as low as $0.45 \mathrm{~g} \mathrm{~cm}^{3}$, which is inferior to the one of a reference membrane made of graphene produced by conventional LPE in NMP $\left(0.71 \mathrm{~g} \mathrm{~cm}^{3}\right)$. The relatively low density of the R6G-FG membrane might be attributed to the presence of R6G molecules, which act as a spacer between the flakes, impeding their restacking during film deposition. ${ }^{76,189}$ Consequently, the laminar R6G-FG membranes were intended to provide expanded nanochannels for high-flux solute filtration (i.e., high water permeability, as demonstrated below).

The electrical volumetric resistivity of the R6G-FG membranes is lower than the one of the reference membrane $\left(0.98 \times 10^{-1} \Omega \mathrm{cm} v s . \sim 2.78 \times 10^{-1} \Omega \mathrm{cm}\right)$. These results agree with the marginal presence of oxygen functionalities, which can also act as architectural spacers between the graphene flakes. ${ }^{190}$ It is noteworthy that both theoretical and experimental studies previously reported that R6G molecules can reduce graphene flakes by removing oxygen functionalities, including epoxy, hydroxyl and carbonyl groups possibly formed in the defective regions of the graphene flakes. ${ }^{148}$

Adhesion force measurements were carried out with an $\mathrm{AFM}^{191,192}$ in humid (relative humidity - RH - 75\%) ambient air (assuming the Lennard-Jones force-separation relation ${ }^{193,194}$ ) to effectively identify the water accessible sites of the R6G-FG membrane. ${ }^{195}$ During the measurements, the adhesion forces between the AFM tip and sample surface are dominated by
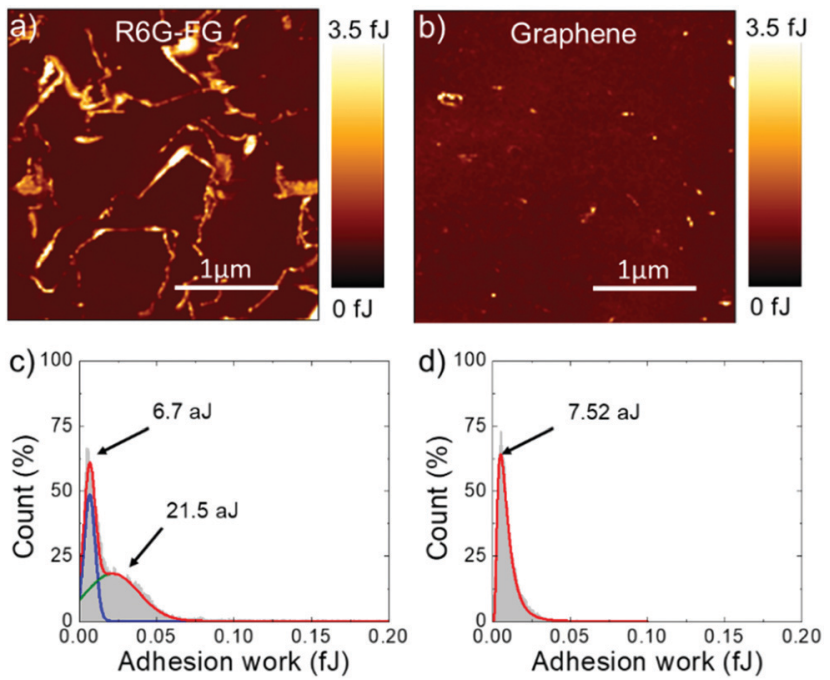

Fig. 4 Evaluation of the adhesion forces on the membrane in humid $(\mathrm{RH} \sim 75 \%)$ ambient air. Adhesion work maps of (a) a R6G-FG membrane (R6G-FG mass loading of $35.8 \mathrm{~g} \mathrm{~m}^{-2}$ ) and (b) a membrane made of graphene produced by conventional LPE in NMP (graphene mass loading of $35.8 \mathrm{~g} \mathrm{~m}^{-2}$ ) (panel b). ( $c$ and d) The adhesion work distributions of the membrane shown in (a) and (b). The corresponding fits are also displayed.

capillary forces, ${ }^{196}$ which depend on the hydrophilicity/ hydrophobicity of the substrate, ${ }^{196-198}$ as well as its roughness. ${ }^{196,197,199}$ In addition, chemical specificity (e.g., the presence of functional groups) can strongly affect the pull-off force at the nano/microscale level. ${ }^{196,200-202}$ Therefore, for the case of the membranes, adhesion force measurements can effectively identify the sites of the R6G-FG membrane accessible to water, ${ }^{195}$ which are typically expressed by hydrophilic porous nano/microdomains. ${ }^{203-205}$ Fig. $4 \mathrm{a}$ and $\mathrm{b}$ show the adhesion work maps of a representative R6G-FG membrane and a reference membrane made of graphene produced by conventional LPE in NMP (material mass loading of $35.8 \mathrm{~g} \mathrm{~m}^{-2}$ for both membranes), respectively. Contrary to the membrane based on graphene produced by LPE in NMP, the R6G-FG membrane manifests elongated nano/microdomains that are more adhesive than the rest of the surface, thus expressing hydrophilic regions. Fig. 4c and d report the adhesion work distribution corresponding to the adhesion work maps. The adhesion work distribution for the R6G-FG membrane can be fitted with two components. The first component, peaking at 6.7 aJ, can be ascribed to the hydrophobic domains of graphene, since it resembles in shape and position the work distribution of the membrane based on graphene produced by LPE in NMP (fitted by a single component peaking at 7.54 aJ). The second component, peaking at 21.5 aJ, lies at an adhesion work higher than the first component, and refers to hydrophilic micro/ nanodomains. The latter are expected to facilitate the access of water to the membrane, ${ }^{49}$ where the water permeation rate is determined by: (1) capillary-driven force; and (2) low-friction flow through the 2D-like channels enclosed by hydrophobic, pristine (non-oxidized) regions of graphene (expanded by R6G molecules acting as spacers). ${ }^{20}$ 
Evaluation of the filtration properties of the graphene-based laminar membranes

The properties and the filtration performance of the as-produced R6G-FG membranes were evaluated in terms of permeability to water (i.e., water permeation rate) and metal ion rejection. The water permeation through the R6G-FG membranes was measured by applying an external pressure in a dead-end filtration mode. ${ }^{206}$ The water permeation rate was found to be $789.6 \mathrm{~L} \mathrm{~m}^{-2} \mathrm{~h}^{-1} \mathrm{bar}^{-1}$ for an $80 \mu \mathrm{m}$-thick membrane (R6G-FG mass loading of $35.8 \mathrm{~g} \mathrm{~m}^{-2}$ ). This value significantly surpasses those of other $2 \mathrm{D}$ material-based laminar membranes proposed in the relevant literature, as shown in Table 1 . In addition, the membrane based on graphene produced by conventional LPE in NMP (mass loading $41.2 \mathrm{~g} \mathrm{~m}^{-2}$ ) showed a water permeation rate of $201.58 \mathrm{~L} \mathrm{~m}^{-2} \mathrm{~h}^{-1} \mathrm{bar}^{-1}$, which is significantly inferior to the one measured for the R6G-FG membrane using a comparable active material mass loading $\left(35.8 \mathrm{~g} \mathrm{~m}^{-2}\right)$. Compared to the R6G-FG membranes, the lower water permeation rate of the membrane based on graphene produced by conventional LPE in NMP is ascribed to the hydrophobicity of the pristine graphene and the absence of spacers (such as R6G molecules in R6GG-FG membranes) between the graphene flakes, which therefore hamper prompt water intercalation. Additional discussion of the high water permeation rate of the R6G-FG membrane is reported in the next section. The ion rejection of the R6G-FG membrane was first evaluated specifically for $\mathrm{Hg}^{2+}$ ICP-OES measurements of filtered $\mathrm{Hg}\left(\mathrm{ClO}_{4}\right)_{2}$ aqueous solution with a $\mathrm{Hg}^{2+}$ concentration $\left(\left[\mathrm{Hg}^{2+}\right]\right)$ of $10 \mathrm{ppm}$.

In fact, on the basis of the use of R6G molecules pre-adsorbed on conductive substrates as fluorescence/SERS chemo-sensors for the selective detection of $\mathrm{Hg}^{2+},{ }^{136-141}$ a distinctive interaction between R6G molecules and $\mathrm{Hg}^{2+}$ was rationally expected to influence the $\mathrm{Hg}^{2+}$ sieving process. Fig. 5a shows the $\mathrm{Hg}^{2+}$ percentage rejection of a R6G-FG membrane with a R6G-FG mass loading of $35.8 \mathrm{~g} \mathrm{~m}^{-2}$ after passing different volumes of

Table 1 Comparison between the water permeation of 2D materialbased membranes reported in relevant literature

\begin{tabular}{llll}
\hline Material & $\begin{array}{l}\text { Thickness } \\
{[\mu \mathrm{m}]}\end{array}$ & $\begin{array}{l}\text { Water permeation } \\
{\left[\mathrm{L} \mathrm{m}^{-2} \mathrm{~h}^{-1} \mathrm{bar}^{-1}\right]}\end{array}$ & Ref. \\
\hline R6G-FG (this work) & 80 & 789.6 & - \\
GO & 0.35 & 1.5 & 207 \\
GO & 2 & 71 & 208 \\
$\begin{array}{l}\text { Carbon nanotube- } \\
\text { intercalated graphene }\end{array}$ & n.d. & 11.3 & 40 \\
GO & $\sim 30$ & 27.6 & 23 \\
$\begin{array}{l}\text { Nanostrand-channelled GO } \\
\text { Corrugated reduced }\end{array}$ & $\begin{array}{l}(15 \text { layers }) \\
\text { GO membrane }\end{array}$ & & \\
KOH-activated & n.d. & 270 & 42 \\
nanoporous graphene & 0.02 & 37 & 41 \\
$\begin{array}{l}\text { MoS } \\
\text { MoS }\end{array}$ & 1.5 & 245 & 209 \\
Crystal violet & 1.7 & 245 & 25 \\
functionalized MoS & 6 & 269.5 & 210 \\
$W_{2}$ & & & \\
$W_{2}$ & 500 & 450 & 211 \\
& 300 & 730 & 211
\end{tabular}

${ }^{a}$ Values measured in dead-end filtration mode.
$\mathrm{Hg}\left(\mathrm{ClO}_{4}\right)_{2}$ solution. A high $\mathrm{Hg}^{2+}$ percentage rejection $(>95 \%)$ is obtained up to $\sim 800 \mathrm{~L} \mathrm{~m}^{-2}$ filtered solution volume normalized to the membrane area. This value can be assumed as the critical filtered solution volume of the membrane, beyond which fading of $\mathrm{Hg}^{2+}$ rejection starts to occur because of saturation of the ion-sieving sites or even a morphology change of the membrane. Fig. 5b shows the $\mathrm{Hg}^{2+}$ percentage rejection of R6G-FG membranes with increasing R6G-FG mass loading (from 17.9 to $71.6 \mathrm{~g} \mathrm{~m}^{-2}$ ) after passing a fixed volume normalized to the area of a $\mathrm{Hg}\left(\mathrm{ClO}_{4}\right)_{2}$ solution of $263.2 \mathrm{~L} \mathrm{~m}^{-2}$. For a R6G-FG mass loading higher than $25 \mathrm{~g} \mathrm{~m}^{-2}$, the $\mathrm{Hg}^{2+}$ rejection is superior to $90 \%$, reaching almost complete rejection (>99\%) for a R6G-FG mass loading superior to $55 \mathrm{~g} \mathrm{~m}^{-2}$, which corresponds to a filtered solution volume normalized to the R6G-FG mass superior to $3 \mathrm{~L} \mathrm{~g}^{-1}$. In contrast, the membrane based on graphene produced by conventional LPE in NMP shows poor $\mathrm{Hg}^{2+}$ rejection capability $(\sim 10 \%)$, thus proving the functional role of R6G molecules adsorbed onto the graphene surface to sieve $\mathrm{Hg}^{2+}$. The $\mathrm{Hg}^{2+}$ rejection capability of the R6G-FG membrane was also investigated by energy dispersive $\mathrm{X}$-ray spectroscopy combined with scanning electron microscopy (SEM-EDS). Fig. 5c shows the presence of material deposits on the surface of the membrane with a R6G-FG mass loading of $35.8 \mathrm{~g} \mathrm{~m}^{-2}$ after the passage of $263.2 \mathrm{~L} \mathrm{~m}^{-2}$ of the $\mathrm{Hg}\left(\mathrm{ClO}_{4}\right)_{2}$ solution. The elemental analysis (Fig. 5d-f) reveals that these deposits are formed by $\mathrm{Hg}$. Interestingly, the membrane made of graphene produced by standard LPE in NMP does not show any presence of $\mathrm{Hg}$ deposits (Fig. S2, ESI $\dagger$ ), in agreement with its poor $\mathrm{Hg}^{2+}$ rejection capability $(\sim 10 \%$, Fig. 5b). The permeation of ionic solutes through R6G-FG membranes was then tested for different alkaline and transition metal ions, i.e., $\mathrm{Ca}^{2+}, \mathrm{Mn}^{2+}, \mathrm{Co}^{2+}, \mathrm{Ni}^{2+}, \mathrm{Cu}^{2+}, \mathrm{Zn}^{2+}$, and $\mathrm{Cd}^{2+}$. As shown in Fig. $5 \mathrm{~g}$, high percentage contents of such ions $\left(\sim 80 \%\right.$ for $\mathrm{Ca}^{2+},>50 \%$ for $\mathrm{Mn}^{2+}, \mathrm{Co}^{2+}, \mathrm{Ni}^{2+}, \mathrm{Cu}^{2+}$, and $\mathrm{Cd}^{2+}$, and $\sim 46 \%$ for $\mathrm{Zn}^{2+}$ ) can pass through the membrane, while proving selective rejection for $\mathrm{Hg}^{2+}$. This result evidences that the ion rejection capability of the R6G-FG membrane is not strictly regulated by size-exclusion effects depending on the interlayer spacing of the graphene flakes, but is also ruled by specific chemical processes (see the working mechanism of R6G-FG membranes sub-section below).

The possibility to recycle the membrane is also important for practical application, since it increases the effective critical filtered solution volume (depending on the $\mathrm{Hg}^{2+}$ concentration of the aqueous solution to be filtered). The regeneration of the active sites for $\mathrm{Hg}^{2+}$ rejection was achieved by washing the R6G-FG membrane in $0.5 \mathrm{M} \mathrm{Bu}_{4} \mathrm{NOH} \cdot 30 \mathrm{H}_{2} \mathrm{O}$. Actually, a similar washing treatment were previously exploited to regenerate the $\mathrm{Hg}^{2+}$-detection capability of R6G-based luminescence sensors, ${ }^{212}$ as well as the adsorption capacity of R6G-based nanocomposites. ${ }^{213}$ Fig. 5 h shows that subsequent washing cycles are effective to desorb $\mathrm{Hg}^{2+}$ from a membrane with a R6G-FG mass loading of $35.8 \mathrm{~g} \mathrm{~m}^{-2}$ which filtered a solution volume normalized to the membrane area of 1842.4 $\mathrm{L} \mathrm{m}^{-2}$ (well above its critical value). After the first washing cycle, $\sim 80 \%$ of the initial $\mathrm{Hg}^{2+}$ rejection capability of the membrane can be successfully restored. 
a)

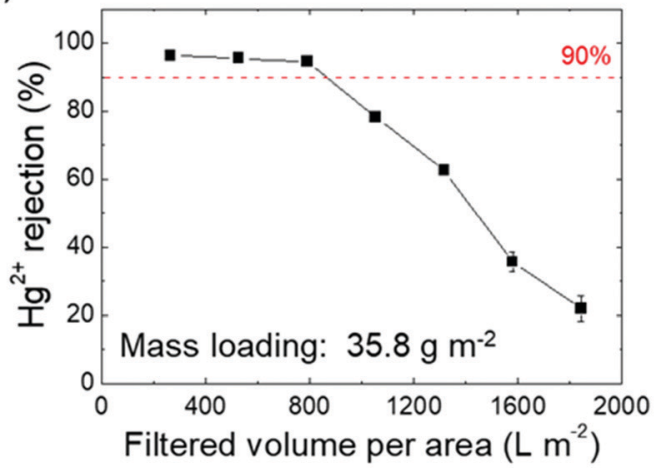

c)

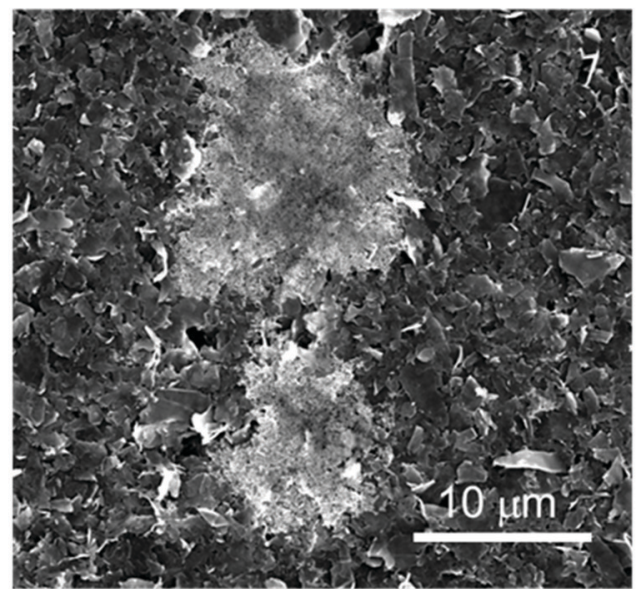

g)

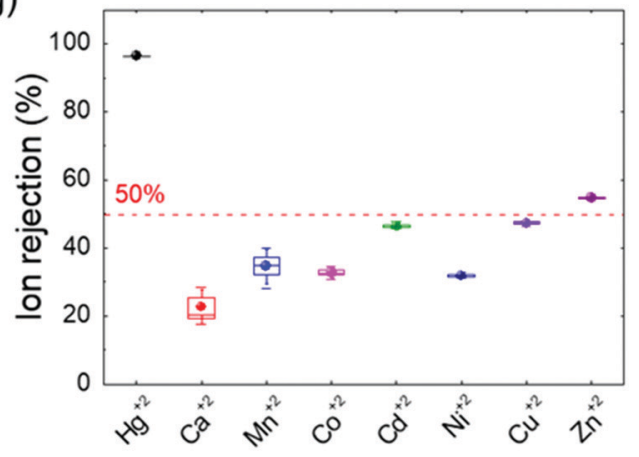

b)

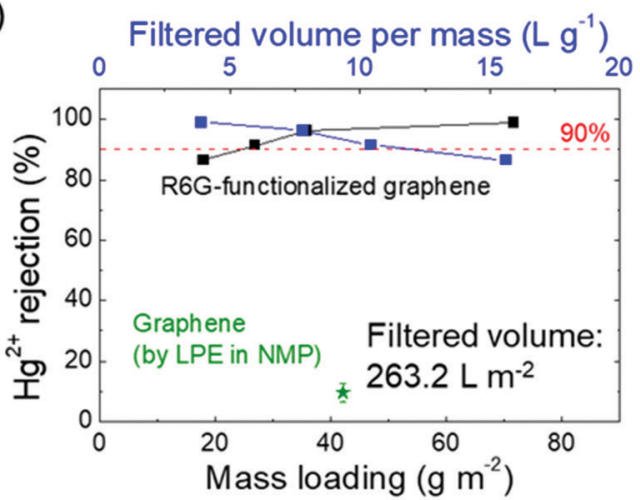

d)

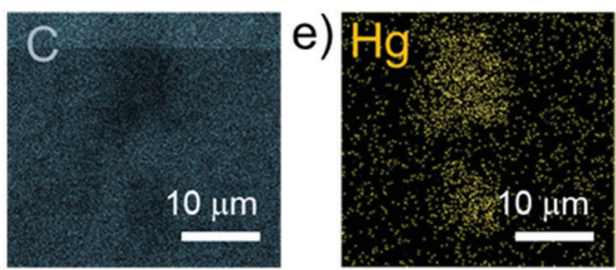

f)

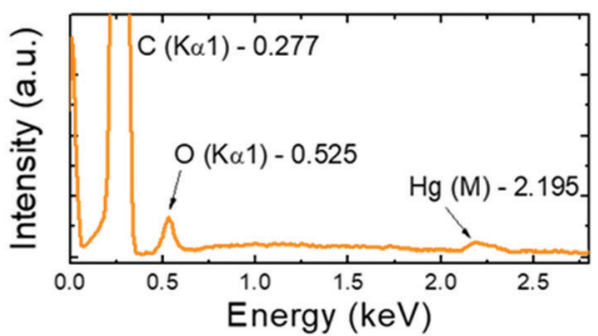

h)

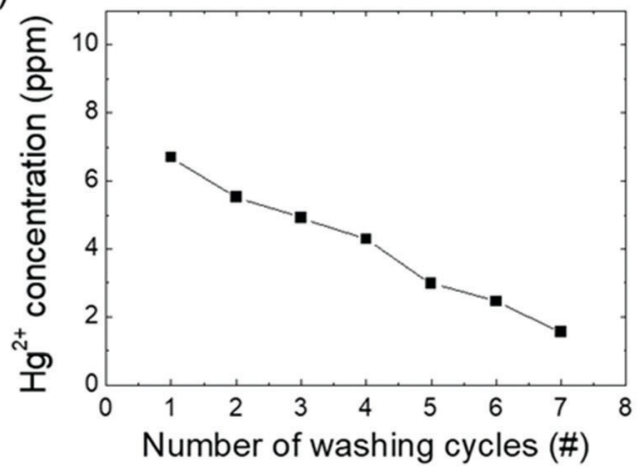

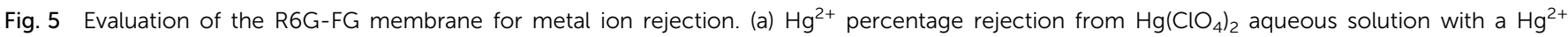
concentration of $10 \mathrm{ppm}$ of the R6G-FG membrane (R6G-FG mass loading of $35.8 \mathrm{~g} \mathrm{~m}^{-2}$ ) as a function of the filtered solution volume (normalized to the area of the membrane). The data are the average values obtained by experiments performed on three different equivalently produced membranes. (b) $\mathrm{Hg}^{2+}$ removal percentage rejection of the R6G-FG membrane as a function of the R6G-FG mass loading (bottom $x$-axis) and filtered solution volume normalized to the mass of R6G-FG (top $x$-axis). A fixed volume of $263.2 \mathrm{~L} \mathrm{~m}^{-2}$ was filtered through the membranes. The Hg $\mathrm{H}^{2+}$ percentage rejection of a membrane made of graphene produced by conventional LPE in NMP is also reported for comparison. (c) Top-view SEM images of a R6G-FG membrane (R6G-FG mass loading of $35.8 \mathrm{~g} \mathrm{~m}^{-2}$ ) after the passage of $263.2 \mathrm{~L} \mathrm{~m}^{-2}$ of $\mathrm{Hg}\left(\mathrm{ClO}_{4}\right)_{2}$ solution $\left(\left[\mathrm{Hg}^{2+}\right]=10 \mathrm{ppm}\right)$. (d and e) Elemental mapping of $\mathrm{C}$ and $\mathrm{Hg}$ for the SEM image and (f) the corresponding EDX spectrum of the R6G-FG membrane imaged in (c). (g) Metal ion percentage rejection of the R6G-FG membrane (R6G-FG mass loading of $35.8 \mathrm{~g} \mathrm{~m}^{-2}$ ) for a filtered aqueous solution volume (normalized to the area of the membrane) of $263.2 \mathrm{~L} \mathrm{~m}{ }^{-2}$ with a $10 \mathrm{ppm}$ metal ion concentration. (h) $\mathrm{Hg}^{2+}$ concentration of the $0.5 \mathrm{M} \mathrm{Bu}{ }_{4} \mathrm{NOH} \cdot 30 \mathrm{H}_{2} \mathrm{O}$ solution passed through a Hg${ }^{2+}$ saturated R6G-FG membrane. $\mathrm{Hg}^{2+}$ saturation has been achieved by filtering through the membrane a volume normalized to the membrane area of $1842.4 \mathrm{~L} \mathrm{~m}^{-2}$ of $\mathrm{Hg}(\mathrm{ClO})_{2}$ aqueous solution $\left(\left[\mathrm{Hg}^{2+}\right]=10 \mathrm{ppm}\right)$.

\section{Working mechanism of the R6G-FG membranes}

The R6G functionalization of graphene flakes has afforded the realization of a filtration membrane with three functional properties: (1) a high water permeation rate; (2) highly selective metal ion rejection capability for $\mathrm{Hg}^{2+}$ from aqueous solution; and (3) recyclability via chemical washing cycles in alkaline conditions. The high-water permeability (up to $789.6 \mathrm{~L} \mathrm{~m}^{-2} \mathrm{~h}^{-1} \mathrm{bar}^{-1}$ for an $80 \mu \mathrm{m}$ thick R6G-FG membrane, see Table 1) is first attributed to 
the low-density $\left(\sim 0.5 \mathrm{~g} \mathrm{~cm}^{-3}\right)$ packed laminar structure in the presence of R6G molecules. In fact, the latter act as spacers between the graphene flakes, which can be easily intercalated by water. ${ }^{19}$ In addition, the peculiar presence of hydrophilic micro/ nanodomains, as observed by adhesion force measurements, can further promote the access of water to the membrane. ${ }^{49}$ Secondly, both capillary-driven force and low-friction flow confined between 2D channels enclosed by hydrophobic, pristine (non-oxidized) regions of graphene can accelerate the passage of water through the membrane. ${ }^{20,214,215}$

The ion selectivity of the R6G-FG membrane for $\mathrm{Hg}^{2+}$ is explained by the competitive adsorption of R6G molecules and metal ions on the surface of the graphene flakes within the membrane (Fig. 6a). At first, R6G molecules are adsorbed onto the graphene surface, forming physiosorbed complexes. As show in the Production and characterization of R6G-FG sub-section, the formation of the complexes originates from the $\pi-\pi$ stacking between the aromatic rings of the R6G molecules and graphene, ${ }^{148-152}$ as well as the electrostatic and non-covalent interactions between positively charged amino groups of R6G molecules and negatively charged intrinsic functional groups of graphene. ${ }^{148,149}$ Such complexes perform as ion-selective nano-traps for $\mathrm{Hg}^{2+}$. In more detail, during the passage of an aqueous solution with metallic contaminants through the R6G-FG membrane, metal ions, especially heavy metal-based ones, can compete with R6G molecules at being adsorbed onto the surface of the graphene flakes. The capability of graphene to adsorb heavy metal ions has been previously reported to be a consequence of van der Waals and electrostatic interactions between the metal ions and negatively charged oxygen groups of graphene. ${ }^{45-47}$ The different affinity of metal ions and R6G molecules to graphene rules the competitive adsorption process. For the metals, the affinity to graphene positively correlates with the metal electronegativity and first stability constant $\left(K_{1}\right)$ of the associated metal hydroxide. ${ }^{47,216}$

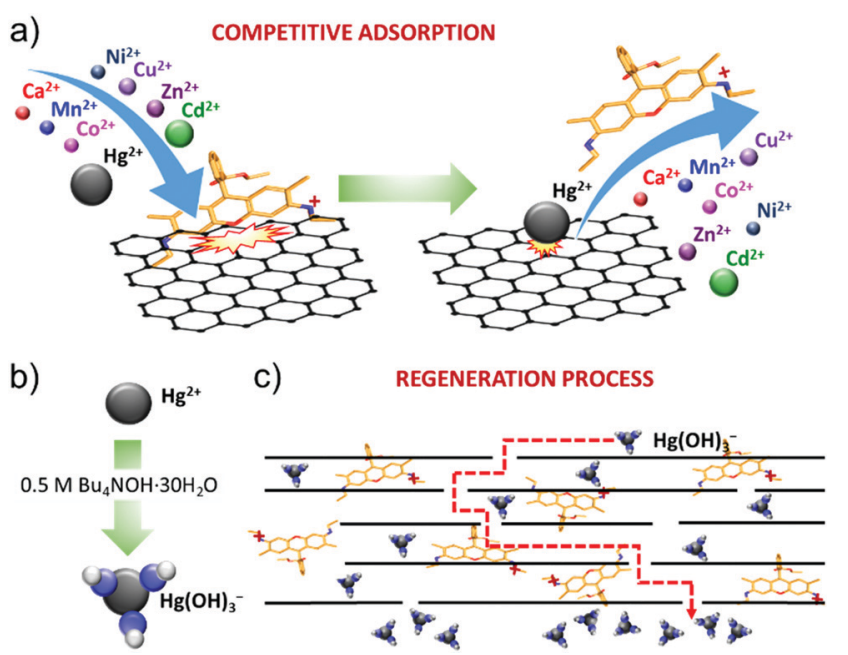

Fig. 6 Working mechanism of R6G-FG membranes. (a) Competitive adsorption of metal ions and R6G molecules resulting in selective $\mathrm{Hg}^{2+}$ rejection from aqueous solution. (b) Formation of mercury hydroxide complexes $\left(\mathrm{Hg}(\mathrm{OH})_{3}{ }^{-}\right.$) in the presence of alkaline conditions $(0.5 \mathrm{M}$ $\mathrm{Bu}_{4} \mathrm{NOH} \cdot 30 \mathrm{H}_{2} \mathrm{O}$ ). (c) Regeneration of the R6G-FG membrane via washing cycles removing $\mathrm{Hg}(\mathrm{OH})_{3}{ }^{-}$
On one hand, the electronegativity of the metal ions represents the attraction of negative charges, and this plays a crucial role in the metal adsorption to the negatively charged surface of graphene. ${ }^{47,216}$ On the other hand, $K_{1}$ of the metal ions determines the speciation of metal ion species, and the formation of hydroxide complexes can alter the order of the metal ions' affinity to graphene predicted by the metal ions' electronegativity. ${ }^{216}$ Consequently, the selective $\mathrm{Hg}^{2+}$ rejection capability of the R6G-FG membranes arises from the high electronegativity $(1.9 \mathrm{eV})^{217}$ and high stability constant $\left(\log K_{1}=\right.$ 10.6) ${ }^{218}$ of $\mathrm{Hg}^{2+}$ compared to those of other metal ions (electronegativity: $1.0 \mathrm{eV}$ for $\mathrm{Ca}^{2+}, 1.5 \mathrm{eV}$ for $\mathrm{Mn}^{2+}, 1.8 \mathrm{eV}$ for $\mathrm{Co}^{2+}, 1.8 \mathrm{eV}$ for $\mathrm{Ni}^{2+}, 2.0 \mathrm{eV}$ for $\mathrm{Cu}^{2+}, 1.6 \mathrm{eV}$ for $\mathrm{Zn}^{2+}$ and $1.7 \mathrm{eV}$ for $\mathrm{Cd}^{2+} ;{ }^{217} \log K_{1}$ : 1.3 for $\mathrm{Ca}^{2+}, 3.4$ for $\mathrm{Mn}^{2+}, 4.3$ for $\mathrm{Co}^{2+}, 4.1$ for $\mathrm{Ni}^{2+}, 6.5 \mathrm{eV}$ for $\mathrm{Cu}^{2+}$, 5.0 for $\mathrm{Zn}^{2+}$ and $3.9 \mathrm{eV}$ for $\mathrm{Cd}^{2+218}$ ). Indeed, only the adsorption of $\mathrm{Hg}^{2+}$ is strongly promoted onto graphene, causing the displacement/ release of $\mathrm{R} 6 \mathrm{G}$ molecules from adsorption sites. In order to further validate the proposed working mechanism of our membranes, PL measurements of the R6G-FG dispersions in water were aquired before and after the addition of $\mathrm{Hg}\left(\mathrm{ClO}_{4}\right)_{2}$ (Fig. S3, $\mathrm{ESI} \dagger)$. The addition of small amounts of a $\mathrm{Hg}\left(\mathrm{ClO}_{4}\right)_{2}$ aqueous solution with $10 \mathrm{ppm}$ of $\mathrm{Hg}^{2+}$ promotes the quenching of the PL emission of the R6G molecules in R6G-FG. However, a further increase of the $\mathrm{Hg}^{2+}$ leads to a partial recovery of the PL emission, indicating that R6G molecules are released from the graphene, which also effectively quenches the PL of the R6G molecules through physisorption interactions (see Fig. 2h). Thus, these PL measurements further support the competitive adsorption of R6G molecules and metal ions on the surface of the graphene flakes across the membrane.

Notably, the high water permeability rate of the R6G-FG membranes is compatible with high membrane thicknesses (e.g., $80 \mu \mathrm{m}$ for a R6G-FG mass loading of $35.8 \mathrm{~g} \mathrm{~m}^{-2}$ ), allowing the proposed physico-chemical working mechanism to be effectively exploited. Since the recyclability experiments in Fig. 6b show that the R6G-FG membrane can be regenerated, the released $\mathrm{R} 6 \mathrm{G}$ molecules are expected to be trapped between the nano-channels of the membrane. As depicted in Fig. 6b, the regeneration mechanism of the membranes in the presence of highly alkaline conditions $\left(0.5 \mathrm{M} \mathrm{Bu}_{4} \mathrm{NOH} \cdot 30 \mathrm{H}_{2} \mathrm{O}\right)$ is then attributed to the formation of mercury hydroxide complexes $\left(\mathrm{Hg}(\mathrm{OH})_{3}{ }^{-}\right){ }^{219}$ These negative complexes are electrostatically repulsed by the negative sites of the graphene surfaces. ${ }^{45,46,220}$ Meanwhile $\mathrm{Hg}(\mathrm{OH})_{3}{ }^{-}$is removed, and trapped R6G molecules can again interact with graphene, sequentially restoring the $\mathrm{Hg}^{2+}$ rejection capability of the membranes. Further optimization of the regeneration process, together with that of the membrane design, is still needed in order to limit the release of R6G molecules during washing cycles.

\section{Conclusions}

In conclusion, a sustainable graphene-based membrane has been proposed for rapid and selective rejection of $\mathrm{Hg}^{2+}$ in aqueous solutions. In order to preclude environmental implications of both the production and the discharge of engineered 
membranes, a non-oxidative, room-temperature and post processing-free "green" method has been developed to simultaneously exfoliate graphite up to single-/few-layer flakes in water and functionalize graphene with cationic rhodamine 6G (R6G), a prototypical cost-effective and non-hazardous organic molecule. The exfoliated samples consist of R6G-functionalized graphene (R6G-FG) flakes with a log-normally distributed lateral dimension and thickness of $194.6 \mathrm{~nm}$ and $1.0 \mathrm{~nm}$, respectively, with a percentage content of $\mathrm{O}<2.5 \%$. The membranes were then fabricated by depositing the as-produced R6G-FG dispersion onto microporous nylon membranes through vacuum filtration. The R6G-FG membranes show an outstanding water permeation rate of $789.6 \mathrm{~L} \mathrm{~m}^{-2} \mathrm{~h}^{-1} \mathrm{bar}^{-1}$ (for an $80 \mu \mathrm{m}$ thick membrane, R6G-FG mass loading of $35.8 \mathrm{~g} \mathrm{~m}^{-2}$ ). The high water permeability is attributed to the low-density packed laminar structure in the presence of R6G molecules acting as a spacer between the graphene flakes, as well as to the presence of hydrophilic micro/nanodomains. In addition, the R6G/graphene complexes perform as ion-selective nano-traps for $\mathrm{Hg}^{2+}$, providing high $\mathrm{Hg}^{2+}$ percentage rejection $(>95 \%)$ up to a critical filtered solution volume (normalized to the membrane area) of $\sim 800 \mathrm{~L} \mathrm{~m}^{-2}$ (for a R6G-FG mass loading of $35.8 \mathrm{~g} \mathrm{~m}^{-2}$ ), which excludes membrane swelling issues typically occurring in twodimensional (2D) material-based membranes. For a filtered solution volume of $263.2 \mathrm{~L} \mathrm{~m}^{-2}$ and a R6G-FG mass loading higher than $30 \mathrm{~g} \mathrm{~m}^{-2}$, the $\mathrm{Hg}^{2+}$ rejection is superior to $90 \%$, reaching almost complete rejection (>99\%) for a R6G-FG mass loading superior to $71.6 \mathrm{~g} \mathrm{~m}^{-2}$ (filtered solution volume normalized to the R6G-FG mass superior to $3 \mathrm{~L} \mathrm{~g}^{-1}$ ). The ion rejection capability of the R6G-FG membrane is strongly selective for $\mathrm{Hg}^{2+}$, as a consequence of the competitive adsorption mechanism between metal ions and R6G molecules with different affinity to interact with the negatively charged surface. Lastly, a washing treatment in highly alkaline conditions has been used to regenerate the $\mathrm{Hg}^{2+}$ rejection capability of the R6G-FG membranes, increasing their effective critical filtered solution volume. Overall, our work rationalizes both the sustainable design and the working mechanism of functionalized graphene-based membranes, providing new insights to overcome the "permeability-selectivity trade-offs" often tackled by laminar 2D material-based membranes.

\section{Conflicts of interest}

There are no conflicts to declare.

\section{Acknowledgements}

The work has been supported by European Union's Horizon 2020 research and innovation program under grant agreements no. 785219 - GrapheneCore2. We thank Electron Microscopy facility - Istituto Italiano di Tecnologia for the support in TEM data acquisition; Gianmarino Pugliese and Nanochemistry facility - Istituto Italiano di Tecnologia for the support in material characterization; Clean Room facility - Istituto
Italiano di Tecnologia for the access to carry out SEM/EDS measurements; and Material Characterization facility - Istituto Italiano di Tecnologia for the access to carry our AFM measurements.

\section{Notes and references}

1 M. A. Montgomery and M. Elimelech, Environ. Sci. Technol., 2007, 41, 17-24.

2 M. Elimelech, J. Water Supply: Res. Technol.-AQUA, 2006, 55, 3-10.

3 M. A. Shannon, P. W. Bohn, M. Elimelech, J. G. Georgiadis, B. J. Mariñas and A. M. Mayes, Nature, 2008, 452, 301.

4 M. A. Shannon, P. W. Bohn, M. Elimelech, J. G. Georgiadis, B. J. Mariñas and A. M. Mayes, Nanoscience and Technology, Macmillan Publishers Ltd, UK, 2009, pp. 337-346.

5 M. Elimelech and W. A. Phillip, Science, 2011, 333, 712-717. 6 R. F. Service, Science, 2006, 313, 1088-1090.

7 J. R. Werber, C. O. Osuji and M. Elimelech, Nat. Rev. Mater., 2016, 1, 16018.

8 R. P. Schwarzenbach, B. I. Escher, K. Fenner, T. B. Hofstetter, C. A. Johnson, U. von Gunten and B. Wehrli, Science, 2006, 313, 1072-1077.

9 Q. Yang, Y. Su, C. Chi, C. T. Cherian, K. Huang, V. G. Kravets, F. C. Wang, J. C. Zhang, A. Pratt, A. N. Grigorenko, F. Guinea, A. K. Geim and R. R. Nair, Nat. Mater., 2017, 16, 1198.

10 L. Chen, G. Shi, J. Shen, B. Peng, B. Zhang, Y. Wang, F. Bian, J. Wang, D. Li, Z. Qian, G. Xu, G. Liu, J. Zeng, L. Zhang, Y. Yang, G. Zhou, M. Wu, W. Jin, J. Li and H. Fang, Nature, 2017, 550, 380.

11 N. Song, X. Gao, Z. Ma, X. Wang, Y. Wei and C. Gao, Desalination, 2018, 437, 59-72.

12 R. K. Joshi, S. Alwarappan, M. Yoshimura, V. Sahajwalla and Y. Nishina, Appl. Mater. Today, 2015, 1, 1-12.

13 S. Homaeigohar and M. Elbahri, NPG Asia Mater., 2017, 9, e427.

14 A. Boretti, S. Al-Zubaidy, M. Vaclavikova, M. Al-Abri, S. Castelletto and S. Mikhalovsky, npj Clean Water, 2018, 1, 5.

15 F. Macedonio, A. Politano, E. Drioli and A. Gugliuzza, Mater. Horiz., 2018, 5, 912-919.

16 Y. C. Woo, L. D. Tijing, W.-G. Shim, J.-S. Choi, S.-H. Kim, T. He, E. Drioli and H. K. Shon, J. Membr. Sci., 2016, 520, 99-110.

17 A. Gugliuzza, A. Politano and E. Drioli, Curr. Opin. Chem. Eng., 2017, 16, 78-85.

18 E. Drioli, A. Ali and F. Macedonio, Desalination, 2015, 356, 56-84.

19 R. K. Joshi, P. Carbone, F. C. Wang, V. G. Kravets, Y. Su, I. V. Grigorieva, H. A. Wu, A. K. Geim and R. R. Nair, Science, 2014, 343, 752-754.

20 R. R. Nair, H. A. Wu, P. N. Jayaram, I. V. Grigorieva and A. K. Geim, Science, 2012, 335, 442-444.

21 P. Sun, M. Zhu, K. Wang, M. Zhong, J. Wei, D. Wu, Z. Xu and H. Zhu, ACS Nano, 2013, 7, 428-437. 
22 Y. Han, Z. Xu and C. Gao, Adv. Funct. Mater., 2013, 23, 3693-3700.

23 M. Hu and B. Mi, Environ. Sci. Technol., 2013, 47, 3715-3723.

24 K. Raidongia and J. Huang, J. Am. Chem. Soc., 2012, 134, 16528-16531.

25 W. Hirunpinyopas, E. Prestat, S. D. Worrall, S. J. Haigh, R. A. W. Dryfe and M. A. Bissett, ACS Nano, 2017, 11, 11082-11090.

26 M.-N. Li, X.-F. Sun, L. Wang, S.-Y. Wang, M. Z. Afzal, C. Song and S.-G. Wang, Desalination, 2018, 436, 107-113.

27 L. Sun, Y. Ying, H. Huang, Z. Song, Y. Mao, Z. Xu and X. Peng, ACS Nano, 2014, 8, 6304-6311.

28 W. Lei, D. Portehault, D. Liu, S. Qin and Y. Chen, Nat. Commun., 2013, 4, 1777.

29 C. E. Ren, K. B. Hatzell, M. Alhabeb, Z. Ling, K. A. Mahmoud and Y. Gogotsi, J. Phys. Chem. Lett., 2015, 6, 4026-4031.

30 Y. Liu, N. Wang, Z. Cao and J. Caro, J. Mater. Chem. A, 2014, 2, 1235-1238.

31 Y. Liu, N. Wang and J. Caro, J. Mater. Chem. A, 2014, 2, 5716-5723.

32 S. Dervin, D. D. Dionysiou and S. C. Pillai, Nanoscale, 2016, 8, 15115-15131.

33 G. Liu, W. Jin and N. Xu, Angew. Chem., Int. Ed., 2016, 55, 13384-13397.

34 M. I. Walker, K. Ubych, V. Saraswat, E. A. Chalklen, P. Braeuninger-Weimer, S. Caneva, R. S. Weatherup, S. Hofmann and U. F. Keyser, ACS Nano, 2017, 11, 1340-1346.

35 N. Wei, C. Lv and Z. Xu, Langmuir, 2014, 30, 3572-3578.

36 N. Wei, X. Peng and Z. Xu, Phys. Rev. E: Stat., Nonlinear, Soft Matter Phys., 2014, 89, 12113.

37 Y. Kang, Z. Zhang, H. Shi, J. Zhang, L. Liang, Q. Wang, H. Ågren and Y. Tu, Nanoscale, 2014, 6, 10666-10672.

38 D. Jang, J. C. Idrobo, T. Laoui and R. Karnik, ACS Nano, 2017, 11, 10042-10052.

39 Y. G. Yan, W. S. Wang, W. Li, K. P. Loh and J. Zhang, Nanoscale, 2017, 9, 18951-18958.

40 Y. Han, Y. Jiang and C. Gao, ACS Appl. Mater. Interfaces, 2015, 7, 8147-8155.

41 L. Qiu, X. Zhang, W. Yang, Y. Wang, G. P. Simon and D. Li, Chem. Commun., 2011, 47, 5810-5812.

42 H. Huang, Z. Song, N. Wei, L. Shi, Y. Mao, Y. Ying, L. Sun, Z. Xu and X. Peng, Nat. Commun., 2013, 4, 2979.

43 G. Shi, Y. Ding and H. Fang, J. Comput. Chem., 2012, 33, 1328-1337.

44 G. Shi, J. Liu, C. Wang, B. Song, Y. Tu, J. Hu and H. Fang, Sci. Rep., 2013, 3, 3436.

45 W. Peng, H. Li, Y. Liu and S. Song, J. Mol. Liq., 2017, 230, 496-504.

46 R. Sitko, E. Turek, B. Zawisza, E. Malicka, E. Talik, J. Heimann, A. Gagor, B. Feist and R. Wrzalik, Dalton Trans., 2013, 42, 5682-5689.

47 J. Xu, Z. Cao, Y. Zhang, Z. Yuan, Z. Lou, X. Xu and X. Wang, Chemosphere, 2018, 195, 351-364.

48 B. Radha, A. Esfandiar, F. C. Wang, A. P. Rooney, K. Gopinadhan, A. Keerthi, A. Mishchenko, A. Janardanan,
P. Blake, L. Fumagalli, M. Lozada-Hidalgo, S. Garaj, S. J. Haigh, I. V. Grigorieva, H. A. Wu and A. K. Geim, Nature, 2016, 538, 222-225.

49 N. Wei, X. Peng and Z. Xu, ACS Appl. Mater. Interfaces, 2014, 6, 5877-5883.

50 S. Zheng, Q. Tu, J. J. Urban, S. Li and B. Mi, ACS Nano, 2017, 11, 6440-6445.

51 S. Kim, R. Ou, Y. Hu, X. Li, H. Zhang, G. P. Simon and H. Wang, J. Membr. Sci., 2018, 562, 47-55.

52 J. Abraham, K. S. Vasu, C. D. Williams, K. Gopinadhan, Y. Su, C. T. Cherian, J. Dix, E. Prestat, S. J. Haigh, I. V. Grigorieva, P. Carbone, A. K. Geim and R. R. Nair, Nat. Nanotechnol., 2017, 12, 546-550.

53 B. Mi, Science, 2014, 343, 740-742.

54 W. Kim and S. Nair, Chem. Eng. Sci., 2013, 104, 908-924. 55 I. V. Vlassiouk, Nat. Nanotechnol., 2017, 12, 1022.

56 A. Morelos-Gomez, R. Cruz-Silva, H. Muramatsu, J. OrtizMedina, T. Araki, T. Fukuyo, S. Tejima, K. Takeuchi, T. Hayashi, M. Terrones and M. Endo, Nat. Nanotechnol., 2017, 12, 1083.

57 F. Bonaccorso, A. Lombardo, T. Hasan, Z. Sun, L. Colombo and A. C. Ferrari, Mater. Today, 2012, 15, 564-589.

58 A. Amiri, M. Naraghi, G. Ahmadi, M. Soleymaniha and M. Shanbedi, FlatChem, 2018, 8, 40-71.

59 V. Nicolosi, M. Chhowalla, M. G. Kanatzidis, M. S. Strano and J. N. Coleman, Science, 2013, 340, 1226419.

60 A. Ciesielski and P. Samori, Chem. Soc. Rev., 2014, 43, 381-398.

61 Y. Hernandez, V. Nicolosi, M. Lotya, F. M. Blighe, Z. Sun, S. De, I. T. McGovern, B. Holland, M. Byrne, Y. K. Gun'Ko, J. J. Boland, P. Niraj, G. Duesberg, S. Krishnamurthy, R. Goodhue, J. Hutchison, V. Scardaci, A. C. Ferrari and J. N. Coleman, Nat. Nanotechnol., 2008, 3, 563.

62 U. Khan, A. O'Neill, M. Lotya, S. De and J. N. Coleman, Small, 2010, 6, 864-871.

63 C.-J. Shih, A. Vijayaraghavan, R. Krishnan, R. Sharma, J.-H. Han, M.-H. Ham, Z. Jin, S. Lin, G. L. C. Paulus, N. F. Reuel, Q. H. Wang, D. Blankschtein and M. S. Strano, Nat. Nanotechnol., 2011, 6, 439.

64 T. Hasan, F. Torrisi, Z. Sun, D. Popa, V. Nicolosi, G. Privitera, F. Bonaccorso and A. C. Ferrari, Phys. Status Solidi, 2010, 247, 2953-2957.

65 L. Najafi, S. Bellani, Re. Oropesa-Nuñez, B. Martín-García, M. Prato, V. Mazánek, D. Debellis, S. Lauciello, R. Brescia, Z. Sofer and F. Bonaccorso, J. Mater. Chem. A, 2019, 7, 25593-25608.

66 W. Zhao, M. Fang, F. Wu, H. Wu, L. Wang and G. Chen, J. Mater. Chem., 2010, 20, 5817-5819.

67 A. E. Del Rio-Castillo, C. Merino, E. Díez-Barra and E. Vázquez, Nano Res., 2014, 7, 963-972.

68 K. R. Paton, E. Varrla, C. Backes, R. J. Smith, U. Khan, A. O'Neill, C. Boland, M. Lotya, O. M. Istrate, P. King, T. Higgins, S. Barwich, P. May, P. Puczkarski, I. Ahmed, M. Moebius, H. Pettersson, E. Long, J. Coelho, S. E. O’Brien, E. K. McGuire, B. M. Sanchez, G. S. Duesberg, N. McEvoy, T. J. Pennycook, C. Downing, A. Crossley, V. Nicolosi and J. N. Coleman, Nat. Mater., 2014, 13, 624. 
69 A. E. Del Rio Castillo, A. Ansaldo, V. Pellegrini and F. Bonaccorso, WO2017089987A1, 2017.

70 A. E. Del Rio Castillo, V. Pellegrini, A. Ansaldo, F. Ricciardella, H. Sun, L. Marasco, J. Buha, Z. Dang, L. Gagliani, E. Lago, N. Curreli, S. Gentiluomo, F. Palazon, M. Prato, R. Oropesa-Nuñez, P. S. Toth, E. Mantero, M. Crugliano, A. Gamucci, A. Tomadin, M. Polini and F. Bonaccorso, Mater. Horiz., 2018, 5, 890-904.

71 S. Bellani, F. Wang, G. Longoni, L. Najafi, R. OropesaNuñez, A. E. Del Rio Castillo, M. Prato, X. Zhuang, V. Pellegrini, X. Feng and F. Bonaccorso, Nano Lett., 2018, 18, 7155-7164.

72 F. Bonaccorso, A. Bortolotta, J. N. Coleman and C. Backes, Adv. Mater., 2016, 28, 6136-6166.

73 L. Najafi, S. Bellani, R. Oropesa-Nuñez, A. Ansaldo, M. Prato, A. E. Del Rio Castillo and F. Bonaccorso, Adv. Energy Mater., 2018, 8, 1703212.

74 L. Najafi, S. Bellani, R. Oropesa-Nuñez, A. Ansaldo, M. Prato, A. E. Del Rio Castillo and F. Bonaccorso, Adv. Energy Mater., 2018, 8, 1801764.

75 L. Najafi, S. Bellani, R. Oropesa-Nuñez, B. Martín-García, M. Prato and F. Bonaccorso, ACS Appl. Energy Mater., 2019, 2, 5373-5379.

76 S. Bellani, B. Martín-García, R. Oropesa-Nuñez, V. Romano, L. Najafi, C. Demirci, M. Prato, A. E. Del Rio Castillo, L. Marasco, E. Mantero, G. D'Angelo and F. Bonaccorso, Nanoscale Horiz., 2019, 4, 1077-1091.

77 L. Carbone, A. E. Del Rio Castillo, J. K. Panda, G. Pugliese, A. Scarpellini, F. Bonaccorso and V. Pellegrini, ChemSusChem, 2020, 13, 1593-1602.

78 V. Romano, B. Martín-García, S. Bellani, L. Marasco, J. Kumar Panda, R. Oropesa-Nuñez, L. Najafi, A. E. Del Rio Castillo, M. Prato, E. Mantero, V. Pellegrini, G. D'Angelo and F. Bonaccorso, ChemPlusChem, 2019, 84, 882-892.

79 W. Yu, T. (Yet) Yu and N. Graham, 2D Mater., 2017, 4, 45006.

80 D. An, L. Yang, T.-J. Wang and B. Liu, Ind. Eng. Chem. Res., 2016, 55, 4803-4810.

81 P. Vandezande, L. E. M. Gevers and I. F. J. Vankelecom, Chem. Soc. Rev., 2008, 37, 365-405.

82 P. Sun, F. Zheng, M. Zhu, Z. Song, K. Wang, M. Zhong, D. Wu, R. B. Little, Z. Xu and H. Zhu, ACS Nano, 2014, 8, 850-859.

83 P. Sun, R. Ma, H. Deng, Z. Song, Z. Zhen, K. Wang, T. Sasaki, Z. Xu and H. Zhu, Chem. Sci., 2016, 7, 6988-6994.

84 A. Striolo, A. Michaelides and L. Joly, Annu. Rev. Chem. Biomol. Eng., 2016, 7, 533-556.

85 I. Vlassiouk, S. Smirnov and Z. Siwy, Nano Lett., 2008, 8, 1978-1985.

86 Y. X. Shen, W. C. Song, D. Ryan Barden, T. Ren, C. Lang, H. Feroz, C. B. Henderson, P. O. Saboe, D. Tsai, H. Yan, P. J. Butler, G. C. Bazan, W. A. Phillip, R. J. Hickey, P. S. Cremer, H. Vashisth and M. Kumar, Nat. Commun., 2018, 9, 2294.
87 V. Georgakilas, M. Otyepka, A. B. Bourlinos, V. Chandra, N. Kim, K. C. Kemp, P. Hobza, R. Zboril and K. S. Kim, Chem. Rev., 2012, 112, 6156-6214.

88 R. Mas-Ballesté, C. Gómez-Navarro, J. Gómez-Herrero and F. Zamora, Nanoscale, 2011, 3, 20-30.

89 A. J. Mannix, B. Kiraly, M. C. Hersam and N. P. Guisinger, Nat. Rev. Chem., 2017, 1, 14.

90 S. Z. Butler, S. M. Hollen, L. Cao, Y. Cui, J. A. Gupta, H. R. Gutiérrez, T. F. Heinz, S. S. Hong, J. Huang, A. F. Ismach, E. Johnston-Halperin, M. Kuno, V. V. Plashnitsa, R. D. Robinson, R. S. Ruoff, S. Salahuddin, J. Shan, L. Shi, M. G. Spencer, M. Terrones, W. Windl and J. E. Goldberger, ACS Nano, 2013, 7, 2898-2926.

91 A. Gupta, T. Sakthivel and S. Seal, Prog. Mater. Sci., 2015, 73, 44-126.

92 H. Huang, K. Schwab and J. G. Jacangelo, Environ. Sci. Technol., 2009, 43, 3011-3019.

93 S. S. Gunderson, W. S. Brower, J. L. O'Dell and E. N. Lightfoot, Sep. Sci. Technol., 2007, 42, 2121-2142.

94 W. Guo, H.-H. Ngo and J. Li, Bioresour. Technol., 2012, 122, 27-34.

95 P. S. Goh, W. J. Lau, M. H. D. Othman and A. F. Ismail, Desalination, 2018, 425, 130-155.

96 A. Grenier, M. Meireles, P. Aimar and P. Carvin, Chem. Eng. Res. Des., 2008, 86, 1281-1293.

97 Y. Bessiere, N. Abidine and P. Bacchin, J. Membr. Sci., 2005, 264, 37-47.

98 A. Abdelrasoul, H. Doan and A. Lohi, Fouling in Membrane Filtration and Remediation Methods, in Mass Transfer-Advances in Sustainable Energy and Environment Oriented Numerical Modeling, ed. H. Nakajima, InTech, Rijeka, Croatia, 2013.

99 X. Cui and K.-H. Choo, Environ. Eng. Res., 2014, 19, 1-8.

100 K. Farahbakhsh, C. Svrcek, R. K. Guest and D. W. Smith, J. Environ. Eng. Sci., 2004, 3, 237-253.

101 M. Beija, C. A. M. Afonso and J. M. G. Martinho, Chem. Soc. Rev., 2009, 38, 2410-2433.

102 Handb. Fluoresc. Dye. Probes, 2015.

103 M. McNutt, Science, 2013, 341, 1430.

104 N. Lubick and D. Malakoff, Science, 2013, 341, 1443-1445. 105 L. D. Hylander and M. Meili, Crit. Rev. Environ. Sci. Technol., 2005, 35, 1-36.

106 E. G. Pacyna, J. M. Pacyna, F. Steenhuisen and S. Wilson, Atmos. Environ., 2006, 40, 4048-4063.

107 J. M. Pacyna, K. Sundseth, E. G. Pacyna, W. Jozewicz, J. Munthe, M. Belhaj and S. Aström, J. Air Waste Manage. Assoc., 2010, 60, 302-315.

108 L. J. Esdaile and J. M. Chalker, Chem. - Eur. J., 2018, 24, 6905-6916.

109 A. G. Bravo, C. Cosio, D. Amouroux, J. Zopfi, P.-A. Chevalley, J. E. Spangenberg, V.-G. Ungureanu and J. Dominik, Water Res., 2014, 49, 391-405.

110 J. M. Esbrí, M. A. López-Berdonces, S. Fernández-Calderón, P. Higueras and S. Díez, Environ. Sci. Pollut. Res., 2015, 22, 4842-4850.

111 Y. Zheng, A. D. Jensen, C. Windelin and F. Jensen, Prog. Energy Combust. Sci., 2012, 38, 599-629. 
112 J. H. Pavlish, E. A. Sondreal, M. D. Mann, E. S. Olson, K. C. Galbreath, D. L. Laudal and S. A. Benson, Fuel Process. Technol., 2003, 82, 89-165.

113 S. X. Wang, L. Zhang, G. H. Li, Y. Wu, J. M. Hao, N. Pirrone, F. Sprovieri and M. P. Ancora, Atmos. Chem. Phys., 2010, 10, 1183-1192.

114 S. Tang, L. Wang, X. Feng, Z. Feng, R. Li, H. Fan and K. Li, Fuel, 2016, 180, 194-204.

115 S. B. T. Sany, A. Salleh, A. H. Sulaiman, A. Sasekumar, M. Rezayi and G. M. Tehrani, Environ. Earth Sci., 2013, 69, 2013-2025.

116 A. Ranjbar Jafarabadi, A. Riyahi Bakhtiyari, A. Shadmehri Toosi and C. Jadot, Chemosphere, 2017, 185, 1090-1111.

117 S. Abdollahi, Z. Raoufi, I. Faghiri, A. Savari, Y. Nikpour and A. Mansouri, Mar. Pollut. Bull., 2013, 71, 336-345.

118 P. Ammann, J. Power Sources, 1995, 57, 41-44.

119 M. Asari, K. Fukui and S. Sakai, Sci. Total Environ, 2008, 393, 1-10.

120 J. Nriagu and C. Becker, Sci. Total Environ, 2003, 304, 3-12.

121 S. Covelli, J. Faganeli, M. Horvat and A. Brambati, Appl. Geochem., 2001, 16, 541-558.

122 H. Edner, P. Ragnarson, S. Svanberg, E. Wallinder, R. Ferrara, B. E. Maserti and R. Bargagli, Sci. Total Environ, 1993, 133, 1-15.

123 A. Biswas, J. D. Blum, B. A. Bergquist, G. J. Keeler and Z. Xie, Environ. Sci. Technol., 2008, 42, 8303-8309.

124 B. Toole-O'Neil, S. J. Tewalt, R. B. Finkelman and D. J. Akers, Fuel, 1999, 78, 47-54.

125 N. Pirrone, P. Costa, J. M. Pacyna and R. Ferrara, Atmos. Environ., 2001, 35, 2997-3006.

126 N. Pirrone, S. Cinnirella, X. Feng, R. B. Finkelman, H. R. Friedli, J. Leaner, R. Mason, A. B. Mukherjee, G. Stracher, D. G. Streets and K. Telmer, Mercury Fate and Transport in the Global Atmosphere: Emissions, Measurements and Models, 2009.

127 D. Malakoff, Science, 2013, 341, 1442-1443.

128 N. E. Selin, Environ. Toxicol. Chem., 2013, 33, 1202-1210.

129 H. Selin, Glob. Environ. Polit., 2014, 14, 1-19.

130 D. A. Atwood and M. K. Zaman, Mercury Removal from Water, in Recent Developments in Mercury Science, ed. D. A. Atwood, Structure and Bonding, Springer, Berlin, Heidelberg, 2006, vol. 120, pp. 163-182.

131 Q. Wang, D. Kim, D. D. Dionysiou, G. A. Sorial and D. Timberlake, Environ. Pollut., 2004, 131, 323-336.

132 A. Shafeeq, A. Muhammad, W. Sarfraz, A. Toqeer, S. Rashid and M. K. Rafiq, Int. Sch. Sci. Res. Innov., 2012, 6, 12-26.

133 A. Azimi, A. Azari, M. Rezakazemi and M. Ansarpour, ChemBioEng Rev., 2017, 4, 37-59.

134 F. M. M. Morel, A. M. L. Kraepiel and M. Amyot, Annu. Rev. Ecol. Syst., 1998, 29, 543-566.

135 R. P. Mason, W. F. Fitzgerald and F. M. M. Morel, Geochim. Cosmochim. Acta, 1994, 58, 3191-3198.

136 J. Xie, Y. Zheng and J. Y. Ying, Chem. Commun., 2010, 46, 961-963.
137 E. Sumesh, M. S. Bootharaju, Anshup and T. Pradeep, J. Hazard. Mater., 2011, 189, 450-457.

138 Z. Wang, M. Yang, C. Chen, L. Zhang and H. Zeng, Sci. Rep., 2016, 6, 29611.

139 H.-Y. Chang, T.-M. Hsiung, Y.-F. Huang and C.-C. Huang, Environ. Sci. Technol., 2011, 45, 1534-1539.

140 X. Ding, L. Kong, J. Wang, F. Fang, D. Li and J. Liu, ACS Appl. Mater. Interfaces, 2013, 5, 7072-7078.

141 J. F. Zhang and J. S. Kim, Anal. Sci., 2009, 25, 1271-1281.

142 L. Najafi, S. Bellani, B. Martín-García, R. Oropesa-Nuñez, A. E. Del Rio Castillo, M. Prato, I. Moreels and F. Bonaccorso, Chem. Mater., 2017, 29, 5782-5786.

143 A. Ansaldo, P. Bondavalli, S. Bellani, A. E. Del Rio Castillo, M. Prato, V. Pellegrini, G. Pognon and F. Bonaccorso, ChemNanoMat, 2017, 3, 436-446.

144 S. Bellani, L. Najafi, A. Capasso, A. E. Del Rio Castillo, M. R. Antognazza and F. Bonaccorso, J. Mater. Chem. A, 2017, 5, 4384-4396.

145 L. Najafi, B. Taheri, B. Martín-García, S. Bellani, D. Di Girolamo, A. Agresti, R. Oropesa-Nuñez, S. Pescetelli, L. Vesce, E. Calabrò, M. Prato, A. E. Del Rio Castillo, A. Di Carlo and F. Bonaccorso, ACS Nano, 2018, 12, 10736-10754.

146 A. Sze, D. Erickson, L. Ren and D. Li, J. Colloid Interface Sci., 2003, 261, 402-410.

147 JPK Instruments AG, JPK Instrument Technical Report: QITM Mode-Quantitative Imaging with the NanoWizard ${ }^{\circledR}$ 3 AFM.

148 K. Zhang, S. Yu, B. Jv and W. Zheng, Phys. Chem. Chem. Phys., 2016, 18, 28418-28427.

149 X. Wang, S. Zhong, Y. He and G. Song, Anal. Methods, 2012, 4, 360-362.

150 K. Fan, Z. Guo, Z. Geng, J. Ge, S. Jiang, J. Hu and Q. Zhang, Chin. J. Chem. Phys., 2013, 26, 252-258.

151 H. Ren, D. D. Kulkarni, R. Kodiyath, W. Xu, I. Choi and V. V. Tsukruk, ACS Appl. Mater. Interfaces, 2014, 6, 2459-2470.

152 X. Zhou, S. He, K. A. Brown, J. Mendez-Arroyo, F. Boey and C. A. Mirkin, Nano Lett., 2013, 13, 1616-1621.

153 C. K. Chua and M. Pumera, Chem. Soc. Rev., 2013, 42, 3222-3233.

154 R. L. D. Whitby, A. Korobeinyk, V. M. Gun'Ko, R. Busquets, A. B. Cundy, K. László, J. Skubiszewska-Ziba, R. Leboda, E. Tombacz, I. Y. Toth, K. Kovacs and S. V. Mikhalovsky, Chem. Commun., 2011, 47, 9645-9647.

155 L. Wu, L. Liu, B. Gao, R. Muñoz-Carpena, M. Zhang, H. Chen, Z. Zhou and H. Wang, Langmuir, 2013, 29, 15174-15181.

156 B. Konkena and S. Vasudevan, J. Phys. Chem. Lett., 2012, 3, 867-872.

157 J. Balapanuru, J.-X. Yang, S. Xiao, Q. Bao, M. Jahan, L. Polavarapu, J. Wei, Q.-H. Xu and K. P. Loh, Angew. Chem., Int. Ed., 2010, 49, 6549-6553.

158 T. L. Doane, C. H. Chuang, R. J. Hill and C. Burda, Acc. Chem. Res., 2012, 45, 317-326.

159 D. W. Johnson, B. P. Dobson and K. S. Coleman, Curr. Opin. Colloid Interface Sci., 2015, 20, 367-382. 
160 J.-B. Wu, M.-L. Lin, X. Cong, H.-N. Liu and P.-H. Tan, Chem. Soc. Rev., 2018, 47, 1822-1873.

161 A. C. Ferrari, J. C. Meyer, V. Scardaci, C. Casiraghi, M. Lazzeri, F. Mauri, S. Piscanec, D. Jiang, K. S. Novoselov, S. Roth and A. K. Geim, Phys. Rev. Lett., 2006, 97, 187401.

162 A. C. Ferrari and D. M. Basko, Nat. Nanotechnol., 2013, 8, 235.

163 C. Thomsen and S. Reich, Phys. Rev. Lett., 2000, 85, 5214.

164 L. Yang, J. Deslippe, C.-H. Park, M. L. Cohen and S. G. Louie, Phys. Rev. Lett., 2009, 103, 186802.

165 A. C. Ferrari and J. Robertson, Phys. Rev. B: Condens. Matter Mater. Phys., 2000, 61, 14095-14107.

166 A. C. Ferrari and J. Robertson, Phys. Rev. B: Condens. Matter Mater. Phys., 2001, 64, 75414.

167 C. Y. Su, Y. Xu, W. Zhang, J. Zhao, X. Tang, C. H. Tsai and L. J. Li, Chem. Mater., 2009, 21, 5674-5680.

168 M. Lotya, Y. Hernandez, P. J. King, R. J. Smith, V. Nicolosi, L. S. Karlsson, F. M. Blighe, S. De, Z. Wang, I. T. McGovern, G. S. Duesberg and J. N. Coleman, J. Am. Chem. Soc., 2009, 131, 3611-3620.

169 A. C. Ferrari, Solid State Commun., 2007, 143, 47-57.

170 M. M. Lucchese, F. Stavale, E. H. M. Ferreira, C. Vilani, M. V. O. Moutinho, R. B. Capaz, C. A. Achete and A. Jorio, Carbon N. Y., 2010, 48, 1592-1597.

171 A. Eckmann, A. Felten, A. Mishchenko, L. Britnell, R. Krupke, K. S. Novoselov and C. Casiraghi, Nano Lett., 2012, 12, 3925-3930.

172 M. S. Dresselhaus, G. Dresselhaus and M. Hofmann, Philos. Trans. R. Soc., A, 2008, 366, 231-236.

173 D. Nuvoli, L. Valentini, V. Alzari, S. Scognamillo, S. B. Bon, M. Piccinini, J. Illescas and A. Mariani, J. Mater. Chem., 2011, 21, 3428-3431.

174 F. Bonaccorso, P.-H. Tan and A. C. Ferrari, ACS Nano, 2013, 7, 1838-1844.

175 L. Jensen and G. C. Schatz, J. Phys. Chem. A, 2006, 110, 5973-5977.

176 Y. Lu, G. L. Liu and L. P. Lee, Nano Lett., 2005, 5, 5-9.

177 R. Lu, A. Konzelmann, F. Xu, Y. Gong, J. Liu, Q. Liu, M. Xin, R. Hui and J. Z. Wu, Carbon N. Y., 2015, 86, 78-85.

178 J. A. Dieringer, K. L. Wustholz, D. J. Masiello, J. P. Camden, S. L. Kleinman, G. C. Schatz and R. P. Van Duyne, J. Am. Chem. Soc., 2009, 131, 849-854.

179 N. H. Kim and K. Kim, J. Raman Spectrosc., 2005, 36, 623-628.

180 A. Siokou, F. Ravani, S. Karakalos, O. Frank, M. Kalbac and C. Galiotis, Appl. Surf. Sci., 2011, 257, 9785-9790.

181 S. Stankovich, D. A. Dikin, R. D. Piner, K. A. Kohlhaas, A. Kleinhammes, Y. Jia, Y. Wu, S. T. Nguyen and R. S. Ruoff, Carbon N. Y., 2007, 45, 1558-1565.

182 J. Díaz, G. Paolicelli, S. Ferrer and F. Comin, Phys. Rev. B: Condens. Matter Mater. Phys., 1996, 54, 8064-8069.

183 J. C. Lascovich, R. Giorgi and S. Scaglione, Appl. Surf. Sci., 1991, 47, 17-21.

184 G. Salitra, A. Soffer, L. Eliad, Y. Cohen and D. Aurbach, J. Electrochem. Soc., 2000, 147, 2486-2493.
185 R. Buzio, A. Gerbi, S. Uttiya, C. Bernini, A. E. Del Rio Castillo, F. Palazon, A. S. Siri, V. Pellegrini, L. Pellegrino and F. Bonaccorso, Nanoscale, 2017, 9, 7612-7624.

186 H. Sun, A. E. Del Rio Castillo, S. Monaco, A. Capasso, A. Ansaldo, M. Prato, D. A. Dinh, V. Pellegrini, B. Scrosati, L. Manna and F. Bonaccorso, J. Mater. Chem. A, 2016, 4, 6886-6895.

187 E. S. Thrall, A. C. Crowther, Z. Yu and L. E. Brus, Nano Lett., 2012, 12, 1571-1577.

188 S. Sil, N. Kuhar, S. Acharya and S. Umapathy, Sci. Rep., 2013, 3, 3336.

189 S. Bellani, E. Petroni, A. E. Del Rio Castillo, N. Curreli, B. Martín-García, R. Oropesa-Nuñez, M. Prato and F. Bonaccorso, Adv. Funct. Mater., 2019, 29, 1807659.

190 C. A. Amadei, A. Montessori, J. P. Kadow, S. Succi and C. D. Vecitis, Environ. Sci. Technol., 2017, 51, 4280-4288.

191 N. F. Martínez and R. García, Nanotechnology, 2006, 17, S167.

192 H.-J. Butt, B. Cappella and M. Kappl, Surf. Sci. Rep., 2005, 59, 1-152.

193 J. E. Lennard-Jones, Proc. Phys. Soc., 1931, 43, 461.

194 N. Yu and A. A. Polycarpou, J. Colloid Interface Sci., 2004, 278, 428-435.

195 N. Hilal, H. Al-Zoubi, N. A. Darwish, A. W. Mohamma and M. Abu Arabi, Desalination, 2004, 170, 281-308.

196 D. L. Sedin and K. L. Rowlen, Anal. Chem., 2000, 72, 2183-2189.

197 M. Farshchi-Tabrizia, M. Kappl and H.-J. Butt, J. Adhes. Sci. Technol., 2008, 22, 181-203.

198 J. Melcher, C. Carrasco, X. Xu, J. L. Carrascosa, J. GómezHerrero, P. José de Pablo and A. Raman, Proc. Natl. Acad. Sci. U. S. A., 2009, 106, 13655-13660.

199 M. Götzinger and W. Peukert, Langmuir, 2004, 20, 5298-5303.

200 E. W. van der Vegte and G. Hadziioannou, Langmuir, 1997, 13, 4357-4368.

201 C. D. Frisbie, L. F. Rozsnyai, A. Noy, M. S. Wrighton and C. M. Lieber, Science, 1994, 265, 2071-2074.

202 J. Zlatanova, S. M. Lindsay and S. H. Leuba, Prog. Biophys. Mol. Biol., 2000, 74, 37-61.

203 D. Cohen-Tanugi and J. C. Grossman, Nano Lett., 2012, 12, 3602-3608.

204 S. P. Surwade, S. N. Smirnov, I. V. Vlassiouk, R. R. Unocic, G. M. Veith, S. Dai and S. M. Mahurin, Nat. Nanotechnol., 2015, 10, 459.

205 B. M. Ganesh, A. M. Isloor and A. F. Ismail, Desalination, 2013, 313, 199-207.

$206 \mathrm{X} . \mathrm{Li}$ and J. Li, in Ecyclopedia of Membranes, ed. E. Drioli and L. Giorno, Springer Berlin Heidelberg, Berlin, Heidelberg, 2015, pp. 1-3.

207 J. Y. Chong, B. Wang and K. Li, Chem. Commun., 2018, 54, 2554-2557.

208 H. Huang, Y. Mao, Y. Ying, Y. Liu, L. Sun and X. Peng, Chem. Commun., 2013, 49, 5963-5965.

209 D. W. Kim, J. Choi, D. Kim and H.-T. Jung, J. Mater. Chem. A, 2016, 4, 17773-17781. 
210 L. Sun, H. Huang and X. Peng, Chem. Commun., 2013, 49, 10718-10720.

211 L. Sun, Y. Ying, H. Huang, Z. Song, Y. Mao, Z. Xu and X. Peng, ACS Nano, 2014, 8, 6304-6311.

212 Z. Wang, C. Dong, M. Wang, Y. Chen and G. Wu, Sep. Sci. Technol., 2014, 49, 2721-2727.

213 M. Wang, Z. Wang, G. Wu, Y. Zhang and A. Wu, Environ. Chem., 2016, 35, 540-547.

214 J. K. Holt, H. G. Park, Y. Wang, M. Stadermann, A. B. Artyukhin, C. P. Grigoropoulos, A. Noy and O. Bakajin, Science, 2006, 312, 1034-1037.
215 M. Majumder, N. Chopra, R. Andrews and B. J. Hinds, Nature, 2005, 438, 44.

216 S. A. Dastgheib and D. A. Rockstraw, Carbon, 2002, 40, 1843-1851.

217 J. A. Dean, Lange's Handbook Of Chemistry, 15th edn, 1999. 218 R. M. Smith, A. E. Martell and R. J. Motekaitis, NIST Stand. Ref. Database 46, 2004.

219 L. Chai, Q. Wang, Y. Wang, Q. Li, Z. Yang and Y. Shu, J. Cent. South Univ. Technol., 2010, 17, 289-294.

220 X. Wang, Z. Chen and S. Yang, J. Mol. Liq., 2015, 211, 957-964. 